\title{
Recent Developments in Graphene Oxide/Epoxy Carbon Fiber-Reinforced Composites
}

\author{
John Keyte, Ketan Pancholi and James Njuguna* \\ Centre for Advanced Engineering Materials, School of Engineering, Robert Gordon University, Aberdeen, United Kingdom
}

The two-dimensional macro molecule graphene and its derivatives have widely been investigated for their application as nanofiller in carbon fiber-reinforced composites (CFRC). Research has progressed from techniques that disperse graphene as a mixing constituent within the composite material to more complex examples where graphene is covalently bonded to fiber, matrix or both via multiple reaction steps. This field of research is multi-disciplinary whereby branches of materials, engineering, polymer science, physics and chemistry often overlap. From the materials engineering perspective, the desire is to discover the novel materials targeting industrial applications and obtain a full understanding of the graphene oxide chemistry and interaction of graphene oxide with a polymer matrix. To date, most of the research is targeted at (i) improving the fiber/matrix

OPEN ACCESS

Edited by:

Antonio Di Bartolomeo,

University of Salerno, Italy

Reviewed by:

Libo Yan,

Technische Universitat Braunschweig, Germany

Dong Xiang,

Southwest Petroleum

University, China

*Correspondence:

James Njuguna

j.njuguna@rgu.ac.uk

Specialty section:

This article was submitted to

Carbon-Based Materials,

a section of the journal

Frontiers in Materials

Received: 12 May 2019 Accepted: 30 August 2019 Published: 09 October 2019

Citation:

Keyte J, Pancholi K and Njuguna J (2019) Recent Developments in Graphene Oxide/Epoxy Carbon Fiber-Reinforced Composites. Front. Mater. 6:224 doi: 10.3389/fmats.2019.00224 interface properties and/or (ii) improving the dispersion of nanofiller within the matrix; both factors ultimately improve composite performance. Organizing that information critically can lead to emergence of a generalization of material design. Therefore, the objective of this work is to critically review current state of art in the field of graphene oxide/epoxy CFRCs and propose the design rules based on current scientific trend and common themes for future works.

Keywords: carbon fiber, modification, graphene, epoxy, nanocomposites, fiber-reinforced composites

\section{INTRODUCTION}

The British physicist, chemist and inventor Sir Joseph Wilson Swan was responsible for giving birth to the carbon fiber industry in the 1860 s when he utilized a form of carbonized paper as a filament in the early development of incandescent light bulbs (The Editors of Encyclopaedia Britannica, 2018). Research concerning carbon fiber materials accelerated through the 1950s and 1960s producing the discovery of polyacrylonitrile (PAN) based carbon fiber by Akino Shindo while working at the Government Industrial Research Institute, Osaka, Japan (GIRIO) (Nakamura et al., 2009). PAN based carbon fibers are generally preferred over pitch or rayon-based alternatives due to their relatively cost-effective manufacture and superior mechanical properties (McConnell, 2008; Naito et al., 2009).

PAN fibers are the foundation of the modern carbon fiber industry and now carbon fibers are routinely combined with a thermoset or thermoplastic polymer matrix to make a rigid, strong and lightweight composites (Masuelli, 2013). The most common thermoset resins in use today are epoxy based due to their mechanical, thermal and corrosion resistant properties (Miracle and Donaldson, 2001; Vautard et al., 2013). This composite appealed the Rolls Royce RB211 turbofan jet-engine that was put in to service in 1971 complete with a single carbon fiber-reinforced composites (CFRC) fan stage (Lazonick and Prencipe, 2005). The trend continues to the present day with the development of General Electric 
GE9X CFRC turbofan for use on the next generation of Boeing 777 aircraft (Trimble, 2013). CFRP is now widely used as aircraft structural components (Soutis, 2005; Njuguna, 2016) however; its technological benefits are not limited to the aerospace industry and has transmitted to many other industries such as in Formula 1 (Savage, 2008) and the automotive industry. For example, use of CFRC material in $903 \mathrm{bhp} \mathrm{McLaren} \mathrm{P1} \mathrm{supercar} \mathrm{has} \mathrm{helped}$ achieving the astonishing power to weight ratio of $647 \mathrm{bhp} / \mathrm{ton}$ (McLaren Technology Group, 2019). With the reduction in the cost, the benefits of these technologies are reaching to general consumers as wider automotive industry is using CFRC in a variety of applications such as bonnets, structural members and vehicle interior finishing (Feraboli and Masini, 2004; Rezaei et al., 2008; Pimenta and Pinho, 2011). CFRCs are also utilized in the building industry to reinforce concrete (Masuelli, 2013; Wang et al., 2017c), process plant/offshore (Garcia et al., 2017; Ojdrovic and Pridmore, 2017) in piping and vessels; renewable energy and in electronic sensor applications (Nihtianov et al., 2017).

Wider use of CFRC has pushed the global carbon fiber demand. The demand is predicted to reach from $\sim 92,000$ ton in year 2018 growing to $\sim 122,000$ ton by year 2022 (Das et al., 2016) and the estimated that the value of the CFRC industry is expected to reach USD 37 billion in 2022 (Marketsandmarkets.com, 2017). It's intuitive that research and development within this industry is required to drive down cost and give rise to new and improved CFRCs with properties that are fine-tuned to ever more specialist and technically demanding applications. To draw comparisons; grade 316 stainless steel is a relatively corrosion resistant grade of steel used in maritime and process plant applications which has a tensile strength of $0.53-0.73 \mathrm{GPa}$, Young's modulus of $200 \mathrm{GPa}$ and density of $8,000 \mathrm{~kg} / \mathrm{m}^{3}$ (European Stainless Steel Development Association, 2007). Aluminum alloy 6061 is utilized in aircraft manufacturing and has a tensile strength of $0.31 \mathrm{GPa}$, Young's modulus of $69 \mathrm{GPa}$ and density of $2,700 \mathrm{~kg} / \mathrm{m}^{3}$ (Holt et al., 1996). In comparison to these two metals, a carbon fiber/epoxy composite constructed from 3 layers of Toray T700 $12 \mathrm{~K}$ fibers $\left[0,90\right.$, and $\left.0^{\circ}\right]$ combined with a Araldite LY5052 resin and HY5052 hardener (bisphenol-A based resin and aromatic diamine hardener) has been shown to possess $1.12 \mathrm{GPa}$ tensile strength, $6.65 \mathrm{GPa}$ Young's modulus and a density of $\sim 2,500$ $\mathrm{kg} / \mathrm{m}^{3}$ (Rahmani et al., 2014).

CFRC offer mechanical properties similar to a high specification metal alloy at significantly reduced weight; however, it is anisotropic material unlike isotropic metallic alloys. CFRC is shown to have a reduction in flexural strength and modulus (Rahmani et al., 2014). The anisotropic behavior is a result of directional property of the carbon fiber and therefore, the mechanical properties are far better in-plane (i.e., along the carbon fiber) than the out of plane properties. In plane properties are primarily influenced by the carbon fiber whereas the out of plane properties are dependent on the matrix strength and particularly the ability of the matrix to transfer flexural load on to the carbon fiber reinforcement (Lv et al., 2011). Therefore, in order to facilitate an efficient transfer of energy from the polymer to the fiber the interface properties are important.
Interfacial properties are influenced by chemical interactions and morphology (Bascom and Drzal, 1987; Drzal et al., 1996; Vautard et al., 2013). Surface properties of both interacting materials largely determines the improved adhesion and therefore, an improvement in mechanical properties.

The epoxy resin is widely used in CFRC and it is a type of polymer characterized often with one or more epoxide functional group with at least one of the epoxide functional group acting as a monomer and terminal unit of the polymer within the structural chain (Lee and Jang, 1998; Miyagawa et al., 2004; Gojny et al., 2014). Epoxy resins are extensively used in the production of lightweight carbon fiber-reinforced composites (CRFP) to deliver desired engineering properties such as high modulus and strength, low creep, superb chemical and thermal stability (Njuguna et al., 2007; Quan et al., 2018). The epoxy/carbon fiberreinforced composite design, just like any other composite, is heavily dependent on the mechanical and thermal properties of the resulting composites of the manufactured epoxy/carbon fiber-reinforced composite withstanding the conditions set by its application requirements.

Carbon fiber surface is non-polar whereas epoxy resins are polar and therefore does not favor an interaction between fiber and matrix. This issue is further exacerbated for highmodulus carbon fibers used in specialist applications. Highmodulus carbon fiber is synthesized from highly aligned PAN precursor and this creates a lower amount of edge defects compared to lower modulus fibers. The reduction in oxygen containing edge defects further reduces the affinity of epoxy to the carbon fiber and can detrimentally affect the interface properties (Bradley et al., 1993; Baral et al., 2008). Carbon fiber has a surface morphology which is generally smooth and hence, it inherently decreases the free surface energy available to favor a good interaction. Resulting poor interface properties can cause CFRCs to delaminate and fail under moderate bending loads. Consequently, a considerable effort has been made in to discovering techniques to promote the fiber/matrix interactions to realize maximum potential of CFRCs.

The objective of this work is to critically review recent advances in carbon fiber, epoxy and graphene composite nanomaterials. The review starts by discussing differences between the graphene derivatives, synthesis techniques and identifying popular methods utilized in CFRC. The main body concentrates on recent discoveries in the fields of carbon fiber surface modification, epoxy polymer modification (covalent and non-covalent), composite processing techniques and nanofiller dispersion in epoxy. The review is generally focused on improvements in mechanical properties and lightly covers thermal and electrical properties only where deemed necessary. Emphasis is paid to molecular interactions throughout discussion because nanoscale relationships ultimately dictate the mechanical, electrical, thermal, rheological and solubility properties of the composite which directly influence industrial processing and consumer application. To the best knowledge of the authors this is the first review which focuses specifically on graphene utilization in CFRC and design rules. 


\section{SYNTHESIS TECHNIQUES FOR GRAPHENE AND ITS DERIVATIVES}

Nanofiller materials for use in industrial CFRC need to meet certain minimum criteria. Production of nanofiller must be attainable at large scales and produce materials possessing properties which facilitate simple processing techniques. This enables the production of nanofiller/CFRCs with minimal process unit operations and cost efficiently. In order to achieve the capacity required for graphene derived nanofiller a top-down method of synthesis is generally employed. These routes can be wet-chemical or mechanical means. The following subsections discuss common top-down synthesis methods and closes by briefly commenting on bottom-up methods.

Graphene oxide (GO) offers additional flexibility at the nanoscale due to the stability of the macromolecule and the multitude of options for further functionalisation which is extremely appealing for modifying both the carbon fiber and polymer phases of CFRCs. Graphene was first isolated at the University of Manchester in 2004 (Novoselov et al., 2004). Graphene is a two-dimensional carbon allotrope with a honeycomb structure of $\mathrm{C}_{6}$ molecules. The $\mathrm{sp}^{2}$ hybridized carbon atoms are bonded to neighboring atoms by three covalent $\sigma$ bonds which leaves the $\pi$-electrons delocalized. This contributes to the phenomenal material properties posed by graphene; 130 GPa intrinsic strength, 1.0 Tpa Youngs modulus, 5,000 W/m $\mathrm{K}$ thermal conductivity, $200,000 \mathrm{~cm}^{2} / \mathrm{v} \mathrm{s}$ and $97.7 \%$ optical transmittance (Lee et al., 2008; Zhu et al., 2010; Pop et al., 2012). The flat structure of graphene gives it an intrinsic surface area of $2,630 \mathrm{~m}^{2} / \mathrm{g}$. Such properties make graphene an ideal candidate for inclusion into composite materials. However, there are drawbacks; these are found in the synthesis of pure graphene and the inherent instability of the material. The most common technique for producing anatomically pure graphene is chemical vapor deposition (CVD) (Phiri et al., 2017) however this process involves large quantities of energy and expensive metal catalyst to convert light $\mathrm{C}_{1}$ or $\mathrm{C}_{2}$ gases in to graphene.

Pure graphene is inherently unstable due to the delocalised $\pi$ electrons. For this reason, graphene is found as graphite in nature because single layer sheets aggregate and fold to increase entropy and increase stability. Fortunately, a derivative of graphene known as "graphene oxide (GO)" which is inherently stable and relatively easy to synthesize using graphite feedstock. The widely accepted Lerf-Klinowski model of GO proposes a $\mathrm{sp}^{2}$ and $\mathrm{sp}^{3} \mathrm{C}_{6}$ skeleton with epoxide and hydroxyl functionalities on the basal plane and carboxylic acid groups on the edges (He et al., 1998; Dreyer et al., 2010). GO is a macro-molecule and non-stoichiometric therefore properties are can be variable depending on degree of oxidation; further observation reported (Feicht et al., 2017) that the in-plane modulus of GO produced by Hummers or Brodie methods varied from 300 to 500 $\mathrm{GPa}$, respectively. Finally, it is now acknowledged that the stronger oxidizing conditions in the former method introduce additional defects on to the surface. GO can be annealed or chemically treated to produce reduced graphene oxide (rGO) which partially reinstates the $\mathrm{sp}^{2}$ carbon on the basal plane and increases electrical and thermal conductivity of the material. GO is stable due to the presence of oxygen functionalities on the basal plane which removes the possibility of $\pi-\pi$ folding and aggregation that is observed with pristine graphene. With such surface properties, the GO dissolve in many polar solvents and fully exfoliate in water (Konios et al., 2014). One can resolve that $\mathrm{GO}$ is an extremely flexible material which shares many attractive attributes with pure graphene but with the advantage that it is simpler to process. Graphene and derivative materials have been utilized extensively in materials science research to produce novel materials with enhanced properties (Sharma et al., 2014; Wei et al., 2015; Atif et al., 2016; Phiri et al., 2017).

\section{Wet-Chemical Synthesis of Graphene Oxide Precursor and Further Processing}

The most common method for producing graphene derived materials for research in to polymer and materials science is the wet-chemical synthesis of graphite oxide from a graphite feedstock (Romero et al., 2018). This technique is the loosely termed "modified Hummers" method which involves the aggressive oxidation of graphite in a concentrated solution of sulphuric acid $\left(\mathrm{H}_{2} \mathrm{SO}_{4}\right)$ and potassium permanganate $\left(\mathrm{KMnO}_{4}\right)$. This method was first reported by Hummers and Offeman in 1958 as aforementioned and with the addition of sodium nitrate $\left(\mathrm{NaNO}_{3}\right)$ (Hummers and Offeman, 1958). The exact reaction mechanism is unknown but the generally accepted pathway (Dreyer et al., 2010; Dimiev and Tour, 2014; Kang et al., 2016) is (1) graphite is mixed with $\mathrm{H}_{2} \mathrm{SO}_{4}$ and the disassociated $\mathrm{H}^{+}$ and $\mathrm{HSO}^{-}$ions of the strong acid penetrate the graphite layers to weaken the attraction and increase layer spacing; (2) side-reactions between $\mathrm{H}_{2} \mathrm{SO}_{4}$ and $\mathrm{KMnO}_{4}$ produce the strong oxidiser manganese heptaoxide $\left(\mathrm{Mn}_{2} \mathrm{O}_{7}\right)$ and the permanganyl cation $\left(\mathrm{MnO}_{3}^{+}\right)$and these species percolate the intercalated graphite while progressively oxidizing the basal plane; (3) after water is added a second oxidation occurs due to permanganate ion $\left(\mathrm{MnO}_{4}^{-}\right)$. The end-product; graphite (or graphene oxide if in aqueous solution) contains hydroxyl, epoxy and carboxylic acid functional groups joined via $\mathrm{sp}^{3}$ carbon while partially retaining a quantity of $\mathrm{sp}^{2}$ hybridized carbon depending on reaction conditions. Figure 1 illustrates the reaction mechanism.

Advantages of the modified Hummers reaction are (1) high yield, (2) highly functionalised and therefore flexible product, (3) tuneable reaction variables that can influence product properties, and (4) relatively simple hardware required to perform the reaction. Researchers have achieved a high product yield (in excess of $30 \mathrm{~g}$ of GO from $15 \mathrm{~g}$ of graphite feedstock) (Zhang et al., 2009; Marcano et al., 2010; Lavin-Lopez et al., 2016). This technique does however have disadvantages, and these are (1) multiple process steps involved in the work-up and (2) single usage of reactants. Work has been done (Lavin-Lopez et al., 2016) to systematically reduce the unit operations from five to three while increasing the reactants to achieve a laboratory scale yield of $34 \mathrm{~g}$ /day with no detrimental impact to the product quality. XPS showed a conventional C/O ratio of 0.74; SEM and XRD showed a dry product size of $\sim 10 \mu \mathrm{m}$ in diameter and 5 layers. Other studies (Ceriotti et al., 2015; Chen et al., 2015) proposed and analyzed several novel work-up methods. 


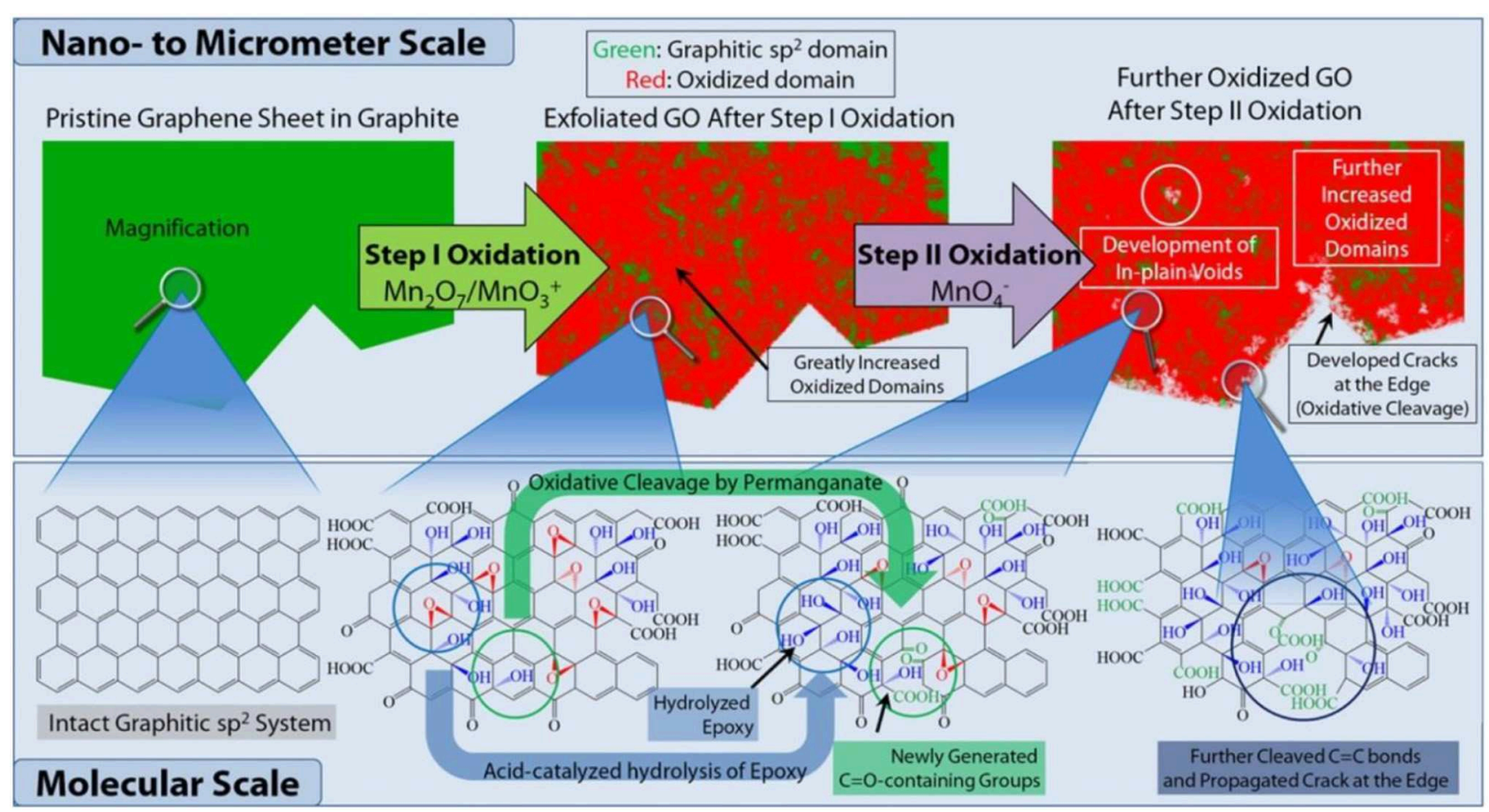

FIGURE 1 | Proposed reaction pathway for the aggressive oxidation of graphite in concentrated $\mathrm{H}_{2} \mathrm{SO}_{4}$ and $\mathrm{KMnO}_{4}$ to produce graphite oxide (modified $\mathrm{Hummers}$ reaction). Reproduced from Kang et al. (2016).

Several techniques reviewed required chemical additives and multiple process steps (Ceriotti et al., 2015). An eloquent filtration step using ceramic paper assisted by a pressurized air driving force to speed-up the process is suitable for up-scalability. Dialysis was proposed (Chen et al., 2015) which proved to be simple and effective however the filtration time of 1 week is not practical for industrial GO production. Green synthesis of GO was demonstrated (Park et al., 2017) using recycled $\mathrm{H}_{2} \mathrm{SO}_{4}$ from the first-stage oxidation reaction mixture. The oxidation took place in a Coyette-Taylor reactor and the vortex induced mixing reportedly reduced the reaction time from 24 to $1 \mathrm{~h}$ to achieve GO recovery rate and quality comparable to the original Hummers and Offeman control method. The reactor produced a mixture with low viscosity $<200 \mathrm{cp}$ (compared to $\sim$ $10,000 \mathrm{cp}$ for control method) which was easily passed through a $25 \mu \mathrm{m}$ poly (tetrafluroethylene)(polypropylene) membrane to extract $\mathrm{H}_{2} \mathrm{SO}_{4}$. The secondary oxidation step was then performed by adding water to the filtrate. The results showed that high quality $\mathrm{GO}$ could be repeatedly produced by recycling the $\mathrm{H}_{2} \mathrm{SO}_{4}$; however further analysis of the recycled acid would be beneficial to quantify the purity and fully understand the effects of this step on the second stage oxidation.

GO is a precursor for graphene material and can be further processed to make rGO; the most popular methods are wet-chemical and thermally annealing (Tang et al., 2012; Abdolhosseinzadeh et al., 2015; Romero et al., 2018). Hydrazine hydrate $\left(\mathrm{N}_{2} \mathrm{H}_{4} \cdot \mathrm{H}_{2} \mathrm{O}\right)$ reducing agent is a popular treatment to remove oxygen functionalities from the basal plane of GO and produces nitrogen gas and water. This partially reinstates the $\mathrm{sp}^{2}$ hybridized carbon network and improves electrical conductivity. There are other wet-chemical methods to produce rGO and GO. For example, a method was demonstrated (Sa et al., 2018) whereby ferrocene $\left(\mathrm{Fe}\left(\mathrm{C}_{10} \mathrm{H}_{10}\right)_{2}\right)$ and nitric acid $\left(\mathrm{HNO}_{3}\right)$ was used and produce $\mathrm{rGO}$ with an enhanced electrical conductivity of $276 \mathrm{~S} / \mathrm{m}$. Thermally annealing GO is highly effective at removing oxygen from the surface (Botas et al., 2013). The annealing process involves heating GO between 300 and $2,000^{\circ} \mathrm{C}$ depending on the desired final product.

One group of researchers (Tang et al., 2012) thermally annealed GO at $1,150^{\circ} \mathrm{C}$ and observed electrical resistance decrease from $10^{6}$ to $10^{-2} \Omega \mathrm{cm}$. This was accompanied by a reduction in $\mathrm{C} / \mathrm{O}$ ratio from 2.8 to 6.9 as identified from $\mathrm{X}$ ray photoelectron spectroscopy (XPS). Raman spectral analysis showed a partial reinstatement of the crystalline surface structure which also supports the conclusion that reduction was successful. Thermal annealment at elevated temperatures has been shown to almost fully re-establish the graphitic structure. Therefore, this technique is useful for fine-tuning the required graphitic structure for the application. As a side note; the same work (Tang et al., 2012) also demonstrated a novel and environmentally friendly method to produce $\sim 1 \mathrm{~nm}$ GO by heating a $0.5 \mathrm{M}$ solution of glucose in an autoclave at $160^{\circ} \mathrm{C}$ for $660 \mathrm{~min}$. Although the method did not produce GO on a similar scale to modified Hummers it is appealing due to the omission of expensive solvents or reactants in the process. This work and similar contributes toward achieving more ethical and 
sustainable sources of graphene for future industrial applications however at present the modified Hummers method is the most practical GO synthesis technique.

\section{Mechanical Exfoliation of Graphite}

Graphite has an extremely strong planar structure with each carbon atom forming three covalent bonds with neighboring atoms. This leaves a spare valence electron per atom which becomes delocalised and free to move between the graphite layers. As the electrons move within the complex temporary $\delta^{+}$ and $\delta^{-}$dipoles are setup and hold the graphite layers together by weak van der Waals forces. Therefore, the anisotropic forces within the graphite complex can be exploited to mechanically separate graphite layers in to single or few sheets. External shear forces can be applied to refine graphene nanoparticles (GNP) from the graphite feedstock. Mechanical exfoliation is attractive because:

- it preserves the properties of pristine graphene,

- expensive reactants are not consumed,

- inherently more environmentally friendly; and

- the process is relatively simple.

An ultrafine mortar grinder has been utilized to exfoliate graphite flake and produce GNP (Antisari et al., 2006). The mortar grinder consists of a rotating bowl and pestle pressed on top that imparts a shear force on the particles. This apparatus was preferred over traditional ball milling due to most of the force being applied along the graphite plane rather than randomly throughout the graphite which helps maintain lateral dimensions of the graphite. X-ray diffraction (XRD) and scanning electron microscopy (SEM) results showed that the graphite flakes were exfoliated from an original size $\sim 200$ diameter and $5.7 \mathrm{~m}^{2} / \mathrm{g}$ BET surface area to GNP sheets $14 \mathrm{~nm}$ thick, $\sim 1-2 \mu \mathrm{m}$ diameter and 43.3 $\mathrm{m}^{2} / \mathrm{g}$ BET surface area after $20 \mathrm{hrs}$ of milling. XRD also showed that the surface crystalline structure of the GNP remained relatively defect free as a result of the exfoliation method. Extending the processing time to $60 \mathrm{hrs}$ showed negligible improvement. The technique was performed in water in which graphene is insoluble. Considering the inherent instability of graphene, it is deduced that re-stacking partially contributed toward the observed plateau. Utilizing a solvent with different polarity could improve the degree of exfoliation.

In other work (Al-Sherbini et al., 2017) planetary ball milling of graphite powder of diameter $<20 \mu \mathrm{m}$ was separately performed in the presence of kerosene and 2-ethyl-hexanol to evaluate the effect that fluid medium viscosity has on the resultant GNP. Solvents with relatively high boiling points $\left(>150^{\circ} \mathrm{C}\right)$ were selected to reduce evaporation during the high energy ball milling process which was performed at $400 \mathrm{rpm}$ for $60 \mathrm{~h}$. Analysis performed using XRD, SEM and Raman spectroscopy qualitatively concluded that the processing in low viscosity kerosene $(1.64 \mathrm{cp})$ produced GNP with fewer layers, more surface defects and smaller sheet size when compared to processing with a more viscous 2-ethyl-hexanol $(10.3 \mathrm{cp})$. The more viscous fluid clearly limited the force imparted to the graphite flakes and directly contributed to the results obtained. Similar research work (Knieke et al., 2010) was able to produce GNP $\sim 3 \mathrm{~nm}$ in size and $\sim 1 \mu \mathrm{m}$ diameter by planetary ball milling $4 \mu \mathrm{m}$ diameter graphite powder in a solvent solution of water and sodium dodecyl sulfate (SDS). The surfactant SDS acts as a stabilizer and interacts with exfoliated graphene sheets to defer re-aggregation. Process variables were changed, and a plateau processing time of $5 \mathrm{~h}$ was identified at $1,500 \mathrm{rpm}$. The systematic approach of quantitatively modeling stress energy allowed the research team to fine-tune processing conditions. This methodology proved successful in producing few layered GNP and has scope for future use.

The suitably termed "Scotch tape method" was described as a means to isolate graphene from graphite (Novoselov et al., 2004). The group repeatedly applied and pealed adhesive tape to highly orientated pyrolytic graphite to progressively separate layer. This method relies on the adhesive force between the tape and graphite exceeding the van der Waals forces of attraction between the graphene sheets in graphite. The tape is subsequently dissolvent in solvent, e.g., acetone, and graphene transferred to a substrate for further study. The major drawbacks with this method are the time and labor-intensive process for minimal product yield.

In brief, GNP produced by scalable mechanical exfoliation techniques can be performed simply and cheaply and without the use of expensive reactants. However, the product is less flexible than graphene oxide and is generally not single layer thick. That said, GNP production can be efficiently up-scaled and significant research effort has gone in to incorporating this material in to carbon fiber and epoxy composites.

\section{Other Graphene Synthesis Techniques}

Anatomically pure graphene is produced by bottom-up CVD synthesis. In a typical process low molecular weight hydrocarbon gas such as methane $\left(\mathrm{CH}_{4}\right)$ is utilized as carbon source and passed over a transition metal catalyst at elevated temperatures $\left(\sim 1,000^{\circ} \mathrm{C}\right)$ in an inert atmosphere (e.g., Argon). The methane molecules are absorbed into the metal surface where they interact with other carbon atoms to form a $\mathrm{C}_{6}$ honeycomb structure. This saturates the metal with carbon material and so the graphene layer is forced to the surface of the catalyst where it is deposited. The graphene/metal catalyst is then further processed; typically, this involves several steps where $\mathrm{SiO}_{2}$ substrate is attached and the metal subsequently chemically etched to remove. This method involved high energy, difficult to handle feedstock (hydrocarbon and inert gas) and multiple workup steps to produce a very low comparable yield to top-down techniques. However, this method produces superior graphene. Presently within the CFRC research arena graphene produced by CVD is not popular due to the aforementioned reasons and the additional difficulty processing substrate-free anatomically pure graphene (Phiri et al., 2017). The single layer inherent instability causes the material to fold-up which negates the benefits. Nonetheless research in the CVD field is popular due to more specialist graphene applications and this work has driven improvements in the technology which may be transferrable to the CFRC industry.

Bulk graphene film with surface area in the range of $\sim \mathrm{cm}^{2}$ has been produced (Reina et al., 2009). The films were constructed of graphene crystals that were 1-12 layers and $\sim 20 \mu \mathrm{m}$ in size. 
CVD was performed $\mathrm{CH}_{4}$ and $\mathrm{H}_{2}$ over a polycrystalline nickel (Ni) film. The Ni film was premade by electron-beam evaporating on silicon-based substrate and thermally annealing to maximize $\mathrm{Ni}$ crystal size; which increases the graphene crystal size. The continuous film production of graphene marked an increase in yield which could appeal to certain graphene applications. In another approach (Wang et al., 2009), $0.05 \mathrm{~g}$ of few layer graphene crystals $(<1 \mu \mathrm{m})$ in size by $\mathrm{CVD}$ of $\mathrm{CH}_{4}$ in Argon (Ar) over a powdered magnesium oxide $(\mathrm{MgO})$ supported Cobalt (Co) catalyst of mass $0.5 \mathrm{~g}$. The catalyst was removed by washing with concentrated hydrochloric acid $(\mathrm{HCl})$ and worked-up in a solution of graphene in ethanol (EtOH). This method has potential because yield approaches the gram scale that is required for materials research; however, for industrial purposes the single usage of catalyst is not appealing unless additional processing steps were employed to recycle.

As with other industries, advances have been made within the CVD field to make processes more environmentally sustainable. Several works (Rahman et al., 2014; Seo et al., 2017) have synthesized graphene by CVD using soybean oil and palm oil feedstock, respectively. The reactants were thermally decomposed to methyl and ethyl hydrocarbons and the CVD reaction proceeded in both cases over $\mathrm{Ni}$ catalysts. The major advantages with this technique are environmentally sustainable carbon source, relatively cheap reactant and ease of reactant handling (liquid as opposed to gaseous phase).

Electrochemical exfoliation is a top-down method that has shown promising results ( $\mathrm{Su}$ et al., 2011). Anodes made from graphite were utilized to perform electrolysis in aqueous $\mathrm{H}_{2} \mathrm{SO}_{4}$ and in the presence of potassium hydroxide $(\mathrm{KOH})$ to reduce $\mathrm{pH}$ and avoid oxidizing the produced graphene. Bi-layer graphene sheets of $\sim 30 \mu \mathrm{m}$ diameter were formed. Raman spectral analysis showed that the graphene produced was of better quality than contemporary methods to synthesize rGO however defects were present which were most likely due to minor oxidation of graphene by $\mathrm{H}_{2} \mathrm{SO}_{4}$. The product was dispersed in dimethylformamide (DMF). The presence of defects is not necessarily a detrimental property as this would have contributed to the solubility of graphene in DMF which is important for processing in CFRC applications. Liquid phase exfoliation was performed (Hernandez et al., 2008) which demonstrated the suitability of the solvent $\mathrm{N}$-methylpyrrolidone (NMP) at suspending graphene at $0.01 \mathrm{mg} / \mathrm{ml}$ concentration. In this work the solvent was selected based on thermodynamic analysis of the enthalpy of mixing. NMP was selected because it has a surface tension within the range of $40-50 \mathrm{~mJ} / \mathrm{m}^{2}$ which is predicted to be compatible with graphite surface energy. Graphite of $\sim 150 \mu \mathrm{m}$ diameter was sonicated in NMP to produce graphene solution with a yield of $1 \% \mathrm{w} / \mathrm{w}$. Characterization of product showed that the graphene was 1-2 layer, $\sim 25 \mu \mathrm{m}$ in diameter and was pristine (i.e., no defects as shown by XPS and Raman spectroscopy).

Although significant advances have been made within CVD and other graphene production techniques the most appealing graphene types for CFRC applications are GNP or GO. The multiple layered structure that GNP exhibits helps stabilize the nanoparticles and reduces aggregation during CFRC preparation.

\section{TYPES OF GRAPHENE OXIDE}

It is important that materials engineers recognize the significant differences between GO and other nanofiller materials such as traditional organic polymers (e.g., starch and cellulose), nanoclays and metallic nanoparticles. Critically, GO is a macromolecule composed of non-stoichiometric amounts of carbon, oxygen and hydrogen. Therefore, there is a wide variance in GO forms and this factor is frequently not given consideration by researchers when constructing nanocomposites. Figure 2 shows typical morphology of GO and experimentation has shown (Muzyka et al., 2017) that there are considerable variations in GO chemistry with different versions of the Hummers method of preparation.

The researchers altered the reaction duration and reactants to explore the effects on chemistry. The XPS analysis showed that the oxygen content in GRO-H1 (1 g Graphite $(1 \mathrm{~g}) ; 20 \mathrm{ml}$ of $\mathrm{H}_{2} \mathrm{SO}_{4} ; 15 \mathrm{ml}$ of $\mathrm{HNO}_{3}, 3 \mathrm{~g}$ of $\mathrm{KMnO}_{4}$ ) and GRO-H2 ( $1 \mathrm{~g}$ Graphite $(1 \mathrm{~g}) ; 30 \mathrm{ml}$ of $\mathrm{H}_{2} \mathrm{SO}_{4} ; 3 \mathrm{~g}$ of $\mathrm{NaNO}_{3}, 3 \mathrm{~g}$ of $\mathrm{KMnO}_{4}$ ) was significantly higher than GRO-D (1 g Graphite ( $1 \mathrm{~g}) ; 15 \mathrm{ml}$ of $\mathrm{H}_{2} \mathrm{SO}_{4} ; 4 \mathrm{~g}$ of $\mathrm{Na}_{2} \mathrm{Cr}_{2} \mathrm{O}_{7}$ ) ad GRO-H3 (1 g Graphite $(1 \mathrm{~g}) ; 22.5 \mathrm{ml}$ of $\mathrm{H}_{2} \mathrm{SO}_{4} ; 0.5 \mathrm{~g}$ of $\mathrm{NaNO}_{3}, 3 \mathrm{~g}$ of $\mathrm{KMnO}_{4}$ ) which demonstrates favorable reaction parameters to achieve a high degree of oxidation. Additionally, FTIR and
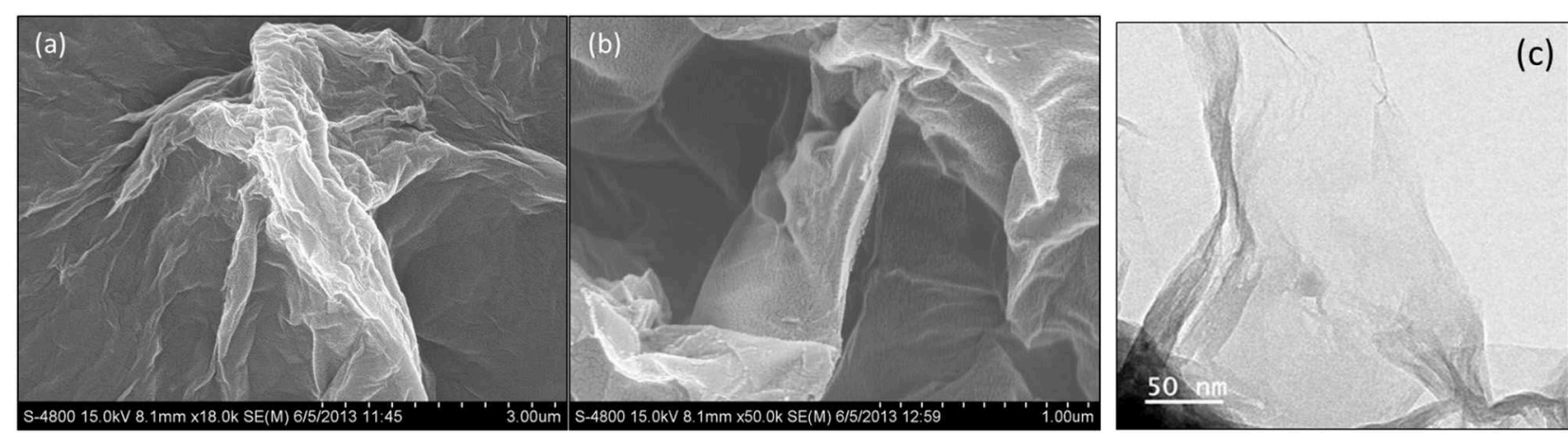

FIGURE 2 | FE-SEM image of (a) GO and (b) rGO, and (c) TEM image of GO. 


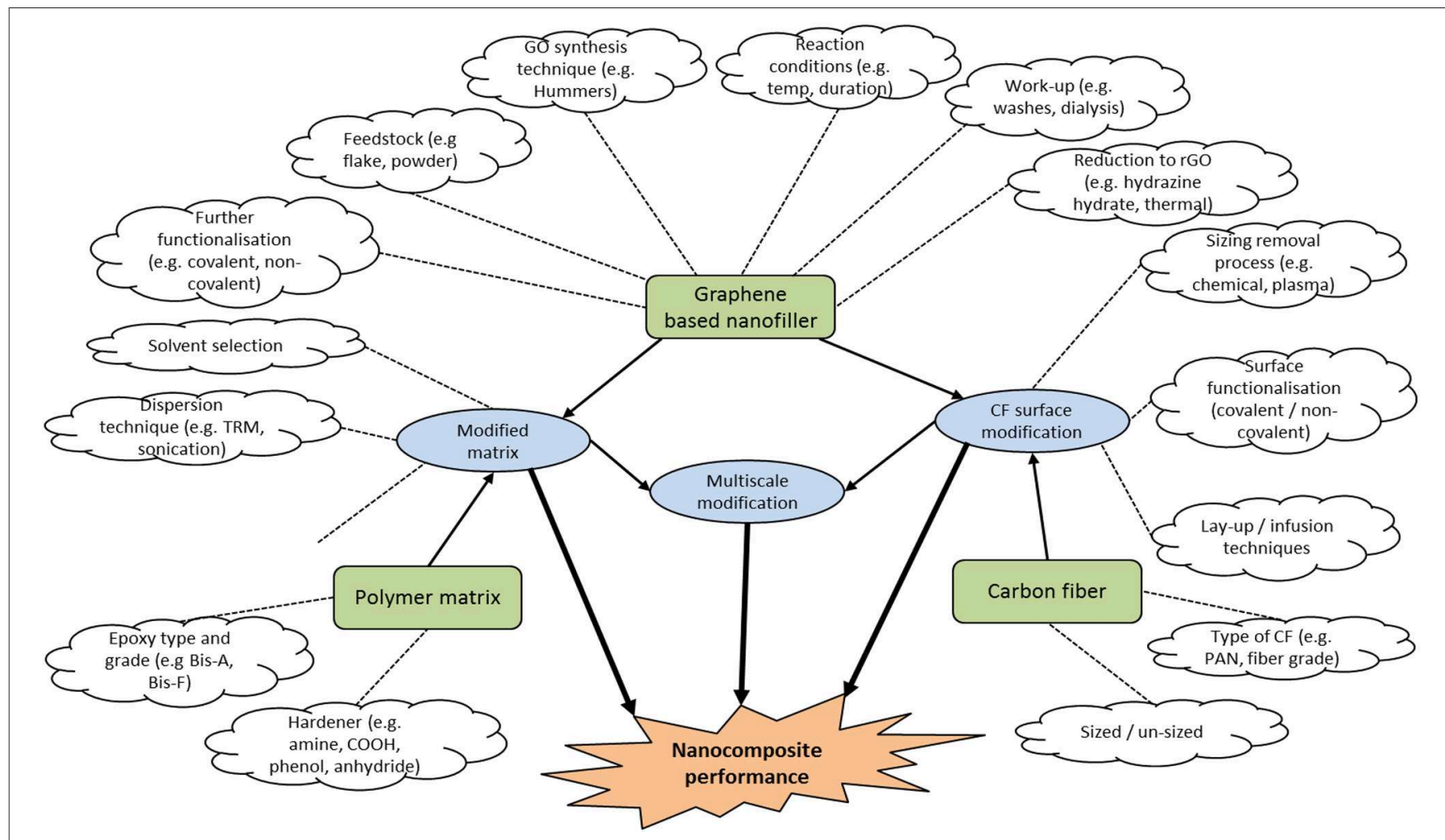

FIGURE $\mathbf{3}$ | Variables that affect nanocomposite performance. Variables are shown in white clouds which can apply to base materials (green boxes) and processes (blue boxes).

XPS showed that GRO-H1 had a higher content of oxygen double bonded to carbon. The elemental analysis results show how the GO product can change significantly depending on reaction parameters. In the materials science context this can greatly affect further opportunities to modify the nanofiller and the performance of the composite. For example, if the materials engineer wishes to further surface functionalise GO then a higher content of reactive oxygen containing species would be desirable. Another interesting observation is that the oxygen content of GRO-H1 and GRO-H2 are comparable which implies similar processability characteristics (i.e., subsequent work-up techniques, handling and flexibility for further chemical functionalisation). However, the reaction times differ from 2 to $24 \mathrm{~h}$ for GRO-H2 and GRO-H1, respectively. The lower residence time for GRO-H2 may be favorable from a cost perspective because this yields product at an accelerated rate.

In other work, a modified Hummers method yielded GO from graphite flakes using $\mathrm{H}_{2} \mathrm{SO}_{4}, \mathrm{KMnO}_{4}$ and $\mathrm{H}_{3} \mathrm{PO}_{4}$ as oxidation reactants (Marcano et al., 2010). This produced GO with a higher oxygen content than the control samples. The C1 XPS spectra was deconvoluted and showed the modified method contained 69\% oxidized carbon compared to $63 \%$ for the traditional Hummers method. The GO produced by this technique contained $31 \%$ of carbon with a $\mathrm{sp}^{2}$ structure compared to $40 \%$ as produced elsewhere (Muzyka et al., 2017) in sample GRO-H1. Further UV-vis, XRD and TEM analysis by Marcano showed that the modified Hummers method product of GO retained a more crystalline $\mathrm{C}_{6}$ structure compared to the traditionally reported Hummers oxidation.

It is natural that changes in reactants and reactant conditions will produce GO with changeable characteristics. Unfortunately, much of the literature assumes that the Hummers oxidation is a simple reaction that lacks in variation and this over simplistic view can miss subtle nuances that the GO type may have on composite performance. There is huge scope for the materials scientist to tailor GO nanofiller to the application. Figure 3 illustrates both the complexity and opportunities for further research by showing the many variables that can affect nanocomposite performance.

At present there is a gap in the literature whereby generally the focus is on constrained to changing a single variable and testing the outcome. Taking a holistic view is important when considering that the purpose of nanocomposite research is to produce viable new materials for use in engineering application; this means that processes need to be as safe, efficient and simple as practically and economically possible. Specific to GO research, materials science has primarily focused on the simple mixing of nanofiller with polymer matrix and constructing a fiber composite which has shown limited and variable results. Figure 2 can be utilized by the materials scientist or engineer as a roadmap to further develop research in to this topic to further expand this field. Having a robust understanding of the GO 
synthesis methods and the variances in potential GO products is critical to develop further research in to carbon fiber surface and polymer matrix modification with the aim of enhancing CFRC performance.

\section{SURFACE MODIFICATION OF CARBON FIBER}

Atoms within the body of a uniform three-dimensional solid material such as diamond are bonded together with each carbon atom interacting covalently with four neighboring atoms. However, at the solid material surface there is an interface where the three-dimensional structure ceases to exist. Atoms on the surface are less tightly bound because they are surrounded by less neighboring atoms. These atoms have free valence electrons, and this creates a surface energy density. The fact that surface energy exists is intuitive when considering the paradoxical scenario where the surface was less energetic than the solid body. This would cause solid material to spontaneously form new surfaces as material from the center expelled energy with increasing entropy; but luckily this is not observed. Carbon fiber is effectively a synonym for graphite fiber because the molecular structure is composed of $\mathrm{C}_{6}$ honeycomb sheets that are randomly folded due to Van Der Waals attractive forces to form the fiber. The solid surface of the fiber is composed of $\mathrm{sp}^{2}$ hybridized carbon graphene sheets. The inherent stability of graphene means that the surface energy of untreated and un-sized carbon fiber is relatively low and in the order of $\sim 30 \mathrm{~mJ} / \mathrm{m}^{2}$ (Paiva et al., 2000). This is an extremely important concept because it influences the wettability of the CFRC interface and directly influences properties.

Liquids display a similar property called surface tension. Cohesive forces are distributed equally within the bulk liquid and this attracts molecules together. Nevertheless, at the surface the attractive forces between the mobile liquid molecules are shared between fewer molecules and create surface tension. Surface tension force is greater than the cohesive force between molecules in the bulk fluid. Epoxy resins DGEBA and tetraglycidyl methylene dianiline (TGMDA) have been shown to have surface tensions of 37 and $41 \mathrm{~mJ} / \mathrm{m}^{2}$, respectively (Page et al., 2001).

Wettability is a measure of how a liquid interacts with a solid surface and is a balance between adhesive forces between the solid/liquid interface and cohesive forces between liquid/liquid molecules (Toshev, 2006; Li et al., 2013). Where cohesion between the liquid molecules is high then the liquid will tend to form more spherical shaped droplets on the surface and will have a lower affinity to interact with the solid surface. Similarly, where a solid has a low surface energy there are minimal intermolecular forces to attract the liquid and liquid/liquid cohesive force dominates. This is observed with carbon fiber where attractive force is generated by the presence of delocalised $\pi$-electrons producing relatively weak Van Der Waals forces. Conversely; a three dimensional covalent or ionic solid will have a large surface energy density. Thermodynamically the material exists as a solid phase due to strong chemical attractions and it is instinctive that the surface energy will exceed the liquid cohesive energy, therefore allowing for good wettability. Generally the surface energy of the solid should be greater than the surface tension of the liquid in order to achieve favorable wettability. Surface energy is difficult to measure directly therefore contact angle is used to estimate surface energy (Toshev, 2006).

Evidently then CFRC using epoxy resins suffer from problems associated with poor wettability. On the macroscale this can lead to poor penetration of fiber by epoxy resin and can create voids that weaken the composite. At the nanoscale the poor intermolecular attractive forces at the interface create an inherent weak zone that is liable to delaminate when stressed. Fortunately, there are many techniques to improve the surface energy of carbon fiber and improve the molecular interaction between fiber and epoxy at the CFRC interface. The surface energy of a solid can be modified by (1) increasing the surface area or (2) increasing the surface energy by activating with chemicals. When a surface is rough the surface area and therefore contact area between surface and liquid increases. This increases the quantity of molecular interactions between the solid and liquid which is observed by a reduction in contact angle (i.e., increase in surface energy). Surfaces can also be activated by adding polar groups (such as carboxylic acid or hydroxyl). These molecules create permanent $\delta^{+}$and $\delta^{-}$dipoles between highly electronegative oxygen and hydrogen which effectively increase the surface energy of the solid. The dipoles will interact favorably with other polar molecules (e.g., organic polymers) via hydrogen bonding. This section specifically reviews recent advances in CFRC interface reinforcement using graphene materials.

\section{Covalent Functionalisation of Carbon Fiber}

Covalent functionalisation of the carbon surface occurs when the fiber surface reacts chemically with another species and as a result both atoms now share to share an electron pair. This is the strongest type of chemical bond between atoms. The methodology is dependent of carbon fiber modulus and the presence of pre-existing sizing. Lower modulus carbon fiber generally contains more surface defects due to the presence of edges and there are oxygen containing moieties at these sites. For higher grade carbon fiber then the surface may require oxidation to add reactive sites however in order to complete this reaction highly ordered $\mathrm{sp}^{2}$ carbon content is reduced which may reduce the mechanical properties of the base carbon fiber. Thus, there is a compromise between desired interfacial properties and overall tensile strength of the carbon fiber. Table 1 shows recent advances in this area and improvements in properties.

The covalent technique has been reported (Koutroumanis et al., 2018) to achieve $130 \%$ improvement in IFSS from 3 to 8 MPa using a laser Raman microscopy characterization method. In this work, low-modulus single de-sized PAN carbon fibers were functionalised with epoxide groups by reacting with 3chloroperoxybenzoic acid (mCPBA) in dichloromethane solvent. XPS spectra were analyzed and showed an increase in surface oxygen content from 9 to $18 \%$ and epoxide species from 9 to $17 \%$. However, increased oxygen content did not damage carbon fiber surface or structure significantly as confirmed by the scanning 
TABLE 1 | A summary of results from literature investigating covalent graft methods to modify the fiber surface properties.

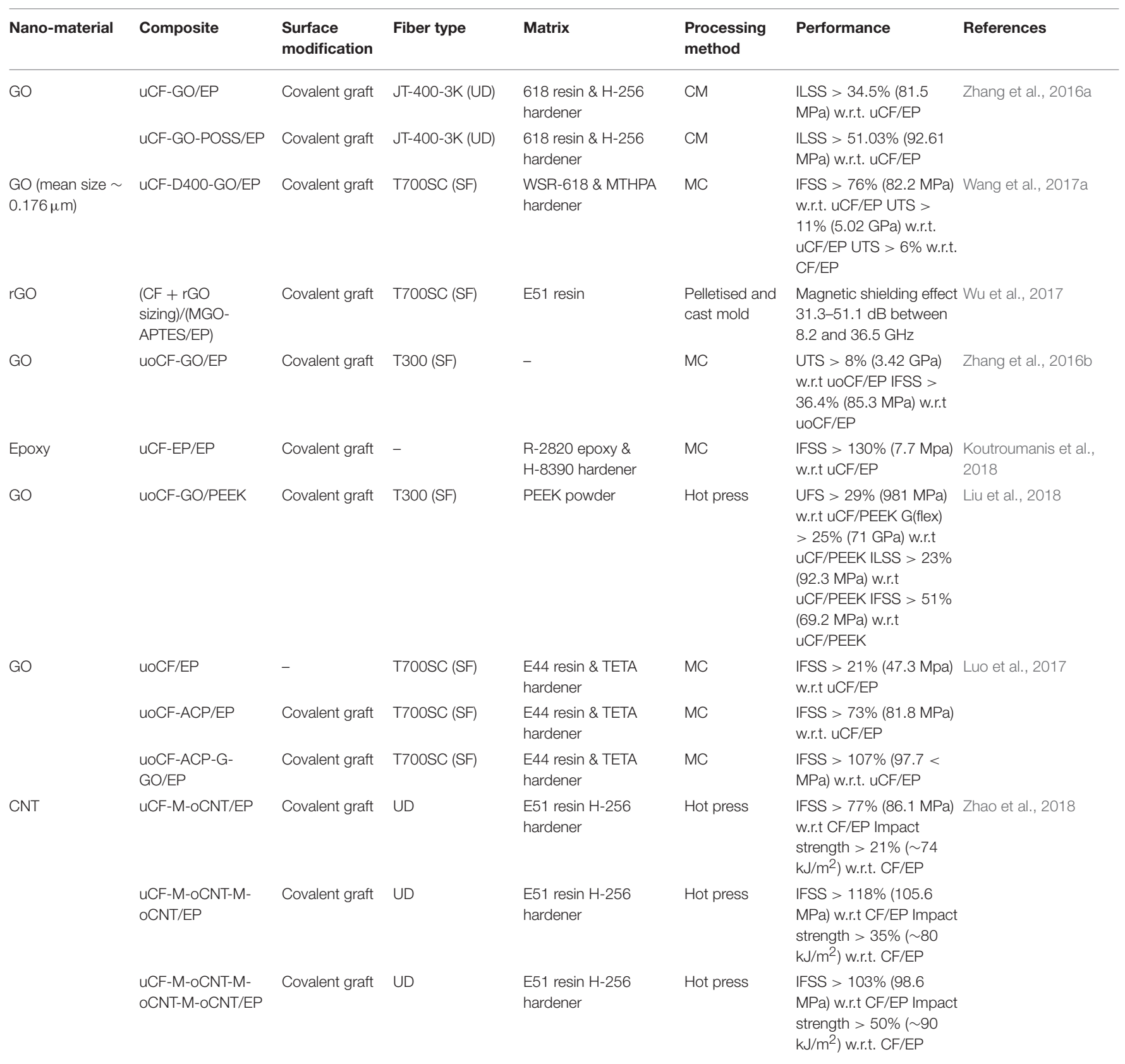

electron microscopy (SEM) images. The milder epoxidation reaction was found to be less harsh than plasma/gamma radiation or electrochemical treatment. To calculate the interfacial shear strength (IFSS), a single fiber composites were prepared using a "water clear" resin/hardener combination of Fibremax R2820/H8390. A correlation was performed to measure the D and G Raman band shifts while simultaneously straining individual filaments. The correlation between strain and shift is then used to calculate IFSS. The epoxide function groups on the carbon fiber participated in the epoxy curing reaction via covalent bonding with hardener and these strong bonds contributed toward the increase in IFSS. This work suggests potentially promising results for IFSS improvements however for materials science applications the experimentation would need to be performed on a larger scale using carbon fiber fabric. In addition, although SEM showed that there were negligible visual differences between treated and untreated fibers it would have been beneficial to characterize surface energy of the fibers to infer whether IFSS improvement was instigated by morphological and/or chemical changes in the fiber surface.

A more aggressive carbon fiber surface treatment was performed on unidirectional PAN fibers (Zhao et al., 2018). 
The experimentation involved multiple unit operations but improved IFSS by $118 \%$ from 45 to $106 \mathrm{MPa}$. Fibers were first de-sized in acetone and then treated in a solution of $\mathrm{AgNO}_{3}$ and $\mathrm{K}_{2} \mathrm{~S}_{2} \mathrm{O}_{8}$ to functionalise with carboxylic acid. Separately CNTs were oxidized in a solution of $\mathrm{HNO}_{3}$ and $\mathrm{H}_{2} \mathrm{SO}_{4}$ to also add carboxylic acid functionalities. The carbon fibers were further functionalised with melanine in $\quad \mathrm{N}$-[(dimethylamino)-1H-1,2,3-triazolo[4,5,6]-pyridin-1ylmethylene]-N-methylmethanaminium hexafluoro-phosphate $\mathrm{N}$-oxide (HATU) reagent which created a peptide bond between the carboxylic acid functional group on the fiber and an amide group on the melanine. The CNTs were subsequently attached to the carbon fiber/melanine compound by reacting in HATU to forming a peptide linkage with melanine. This process was repeated up to three times to add progressively stack CNTs on to the surface. Characterization by XPS showed that the ratio of peptide to carboxylic acid reduced with additional reaction cycles which supported the conclusion that peptide bonds were forming in place of carboxylic acid sites. SEM was used to show successful progressive stacking of CNTs as roughness became more visually apparent. Surface energy measurement showed a reducing contact angle with additional functionalisation reactions proving that the surface chemistry and/or morphology had changed and demonstrating that this had improved wettability and therefore interfacial properties.

Composites were made by combining the surface modified carbon fiber with E-52 bisphenol-A based epoxy and cured with 4,4-methylenebis(2-ethylbenzenamine) hardener in a compression mold. Mechanical testing showed that the best performing composite had undergone two cycles of CNT addition which showed an IFSS improvement of $118 \%$ compared to $103 \%$ for three cycles. The reduction of interface mechanical performance with more than two cycles was attributed to steric hindrance caused by excessive CNTs on the carbon fiber. Impact strength tests showed an improvement of $50 \%\left(90 \mathrm{~kJ} / \mathrm{m}^{2}\right), 35$ and $21 \%$ for three, two and one cycle(s), respectively. The researchers concluded that this was due to the increased CNT layering acting to deflect impact forces from transmission into the carbon fiber and therefore dampened the forces. The tensile strength of single treated carbon fibers showed a marginal improvement compared to untreated which suggests that this treatment does not adversely affect mechanical properties of the fiber. SEM analysis of the IFSS mechanical tests showed significant residual epoxy on the fiber surface therefore the surface modification had well-reinforced the interface to such an extent that the matrix had become the weak point. Considering that CNTs and carbon fiber are highly conductive then electrical properties of these composites should be characterized in future to show whether there are viable applications. Additionally, this technique may be further developed to assess the suitability of GO as a surface modification. Considering that GO contains edge carboxylic acid groups then this would eliminate the need to perform additional functionalisation on GO. This would potentially reduce unit operations and offer a more efficient process for upscaling.

Another covalent functionalisation technique was demonstrated (Luo et al., 2017) where $\mathrm{HNO}_{3}$ was used to oxidize T700 PAN fibers and add hydroxyl and carboxylic acid functional groups to the fiber surface. The functionalised fibers were then reacted with hexacholorocyclotriphosphazine (HCCP) where hydrogen atoms in the hydroxyl group were substituted with chlorine atoms on HCCP to covalently link fiber and HCCP. The compound was further reacted with 4,4-oxydiphenylamine (ODA) and HCCP in a polycondensation reaction to coat the carbon fiber amine capped polyphosphazene. A primary amine group on ODA reacts with a chlorine molecule on HCCP; the chlorine molecule is substituted to leave a covalent secondary amine linkage between HCCP and ODA. The reaction stoichiometry was designed to leave excess ODA primary amine sites available for further reaction. Separately GO was produced by Hummers method and functionalised in two stages; first HCCP was covalently bonded to the edges of GO at carbonyl sites and then reacted further with glycidol where the chlorine atoms were substituted with the oxygen group on the glycidol. This produced epoxy functionalised GO. XPS and FTIR was used to show the presence of additional epoxy groups present on functionalised GO which inferred covalent functionalisation. XPS also showed the presence of nitrogen and phosphorus to increase after carbon fiber had been functionalised with HCCP and ODA.

The functionalised GO and functionalised carbon fiber were reacted together and covalently linked via peptide bonds. SEM imaging of the product showed GO sheets protruding perpendicularly outwards from the carbon fiber surface. Composites were constructed using functionalised carbon fiber and E44 bisphenol-A based resin, cured with TETA hardener. Mechanical testing of the interface was performed by microbond analytical instrument on single fibers. The improvement in mechanical performance would suggest a covalent reinforcement of the interface however without supporting FTIR analysis and discussion it is difficult to draw any firm conclusion. In addition, SEM was performed on functionalised GO only and not on the samples used in mechanical testing, therefore a conclusion cannot be made as to where the weak-point is. The research is and characterization offers a novel method to ensure GO is attached covalently and perpendicular to the carbon fiber. This approach will avoid potential steric effects that would otherwise have been seen had GO wrapped around the carbon fiber. The method the researcher team employed was to functionalise the edges of GO, and the SEM characterization seems to prove that this approach was successful. This technique to orientate GO relative to the carbon fiber is useful for future work as this ought to benefit interfacial properties.

Simpler methods have been employed to covalently functionalise carbon fiber with $\mathrm{GO}$ which have also produced marked improvements in mechanical properties. One research group (Wang et al., 2017a) functionalised standard modulus T700 carbon fiber by washing in acetone to remove sizing and then reacting with $\mathrm{HNO}_{3}$ to add carboxylic acid groups to the surface. Polyether amine of circa $400 \mathrm{~g} / \mathrm{mol} \mathrm{molecular}$ weight was reacted with the carbon fiber in the presence of HATU to form a peptide bond. FTIR supported this conclusion with the appearance of new peaks at 3,500 and $940 \mathrm{~cm}^{-1}$ which were attributed to $\mathrm{N}-\mathrm{H}$ stretch of amino groups, and at 1,450 $\mathrm{cm}^{-1}$ attributed to $\mathrm{C}-\mathrm{N}$ stretch. XPS supported the FTIR 
characterization and deconvoluted $\mathrm{C} 1$ spectra showed peaks at 285.7 and $287.9 \mathrm{eV}$ indicating $\mathrm{C}-\mathrm{N}$ and $-\mathrm{N}-\mathrm{C}=\mathrm{O}$ bonds. $\mathrm{GO}$ of varying molecular weights was reacted with functionalised carbon fiber in the presence HATU to covalently modify the surface. GO was classified determining on its location within a centrifuged supernatant with low molecular weight (MWt) GO extracted from the surface section and heavier MWt from the lower section. SEM showed average size of 1.108, 0.176, and $0.060 \mu \mathrm{m}^{2}$. Interesting the $\mathrm{GO} \mathrm{C} / \mathrm{O}$ ratio was 0.85 in low MWt compared to 0.79 in high MWt. Two conclusions can be made; firstly that the higher oxygen content would improve the stability of the $\mathrm{GO}(\mathrm{aq})$ solution therefore it would be expected to find GO of higher oxygen content near the supernatant surface. Secondly, the residue is more likely to contain larger MWt molecules and this could be caused by the presence of (1) physically larger particles and (2) lower oxygen content GO tending to agglomerate together to form larger particles.

Composite samples were created by curing WSR-618 bisphenol-A based epoxy resin with methyltetrahydrophthalic anhydride (MTHPA) anhydrite hardener. The medium MWt GO demonstrated the best mechanical performance with an IFSS improvement of $76 \%$ from 47 to $82 \mathrm{MPa}$ and the ultimate tensile strength also improved by $11 \%$ to $5 \mathrm{GPa}$. Contact angle was lowest and surface energy highest for the midMWt GO/carbon fiber sample which supports that interfacial mechanical performance was found to be optimum. SEM analysis showed that low and high MWt GO tended to lay flat on the fiber surface and conversely mid-MWt was perpendicular to the surface. It was reasoned that the higher oxygen content in lowMWt GO would have possibly formed amine bonds between functional groups on the GO basal plane and the fiber surface causing it to lay flat. For high MWt-GO the physical size meant that it was likely to lay flat on the fiber surface. SEM analysis of the mechanical samples supported this theory as for mid-MWt GO it appeared to remain on the surface of the fiber and showed evidence of matrix cohesion failure rather than adhesion failure between matrix and fiber. This research work, in a similar way to other reported work (Zhao et al., 2018), demonstrated that there is a limit to what can be achieved through surface modification. A key finding made (Wang et al., 2017a) is that the materials scientist must tailor the GO macro-molecules to the design intent of the experiment; in this work there was an optimal size and $\mathrm{C} / \mathrm{O}$ ratio of GO. A full understanding of GO synthesis technique and resultant chemical and physical properties is critical to ensure success. This also applies to other macro-molecules utilized in fiber surface modification.

Another simple covalent graft of GO to carbon fiber surface was performed (Zhang et al., 2016b). In their work low modulus carbon fiber was desized in acetone and oxidized in $\mathrm{HNO}_{3}$ to add carboxylic acid functional groups. The fiber was further treated with $\mathrm{SOCl}_{2}$ to make acyl chloride functionalised fiber with functional group -COCl. GO was prepared by a facile modified Hummers method and reacted with ethylenediamine (EDA) to functionalise the edges with primary amine. The modified fiber and GO were then covalently linked via a peptide bond by reacting together in tetrahydrofuran (THF). FTIR, XPS and TGA showed the successful grafting of GO on to the fiber surface and wettability testing showed an improvement after surface modification. Composites were prepared by compression molding using bisphenol-A based epoxy resin and H-256 amine hardener (3,3'-diethyl-4,4' diaminodiphenylmethane). Mechanical testing showed that IFSS had improved by $36 \%$ from 63 to $85 \mathrm{MPa}$ and UTS had improved by $8 \%$ from 3.17 to $3.42 \mathrm{GPa}$. SEM imagery of the fracture surface shows minimal pull-out at the fracture surface in the sample that had carbon fibers modified covalently with GO which shows a strong fiber/matrix interfacial strength. The study provided an example of an up-scalable modification technique on multiple fibers in contrast to much of the research which has focused on single fiber modification and testing.

The research team further improved their work by including polyhedral oligomeric silsequioxane (POSS) in to the surface modification (Zhang et al., 2016a). POSS is a 3-dimensional roughly cubic shaped inorganic molecule. In this work octagylcidyl dimethylsilyl POSS was utilized and the chemical has an epoxy containing chain connected to each corner of the cube structure. The methodology was similar to the earlier work (Zhang et al., 2016b) however an additional reaction was performed to covalently link POSS to the fiber modified with GO$\mathrm{NH}_{2}$. Composite samples with epoxy resin were prepared and mechanically tested. ILSS showed an improvement of $51 \%$ from 61 to $93 \mathrm{MPa}$, which was an enhancement when compared to the original work. The team concluded that the improved interfacial properties were due to the epoxy functional groups on POSS participating in the epoxy curing reaction.

There are many different techniques which can be utilized to modify the surface of carbon fibers. The challenge for the materials scientist is to find a technique with can be scaled-up for industrial application. Inevitably this will involve a compromise between ease of processabilty and mechanical performance. The challenge is therefore to seek out simpler more facile modification techniques that yield improved mechanical performance.

\section{Electrophoretic Deposition of GO on Carbon Fiber}

The electrophoretic deposition technique can be used to deposit nanofiller on to the fiber surface. The procedure typically involves immersing the fiber into a solution containing colloidal particles and passing an electric current through the fiber. The electric field imparts an attractive force on the charged nanoparticles causing them to deposit on the electrode with the opposite charge. For carbon fiber and graphene materials the fiber is setup as the cathode and the negatively charged graphene-based nanoparticles are attracted to the positively charged fiber surface and are deposited. Table 2 shows recent advances in this area and improvements in properties reported in the literature.

A series of works (Deng et al., 2015, 2016; Yao et al., 2018) were completed which used electrophoretic deposition (EPD) to modify the carbon fiber surface with GO and CNT sizing; composite samples were made with epoxy and mechanically tested which achieved improvements in IFSS. Compared to the unsized carbon fiber epoxy with IFSS $48 \mathrm{MPa}$ the addition of GO and CNT increased IFSS by $63 \%$ to $79 \mathrm{MPa}$ and $89 \%$ to 91 
TABLE 2 | A summary of results from literature investigating electrophoretic deposition technique to modify the fiber surface properties.

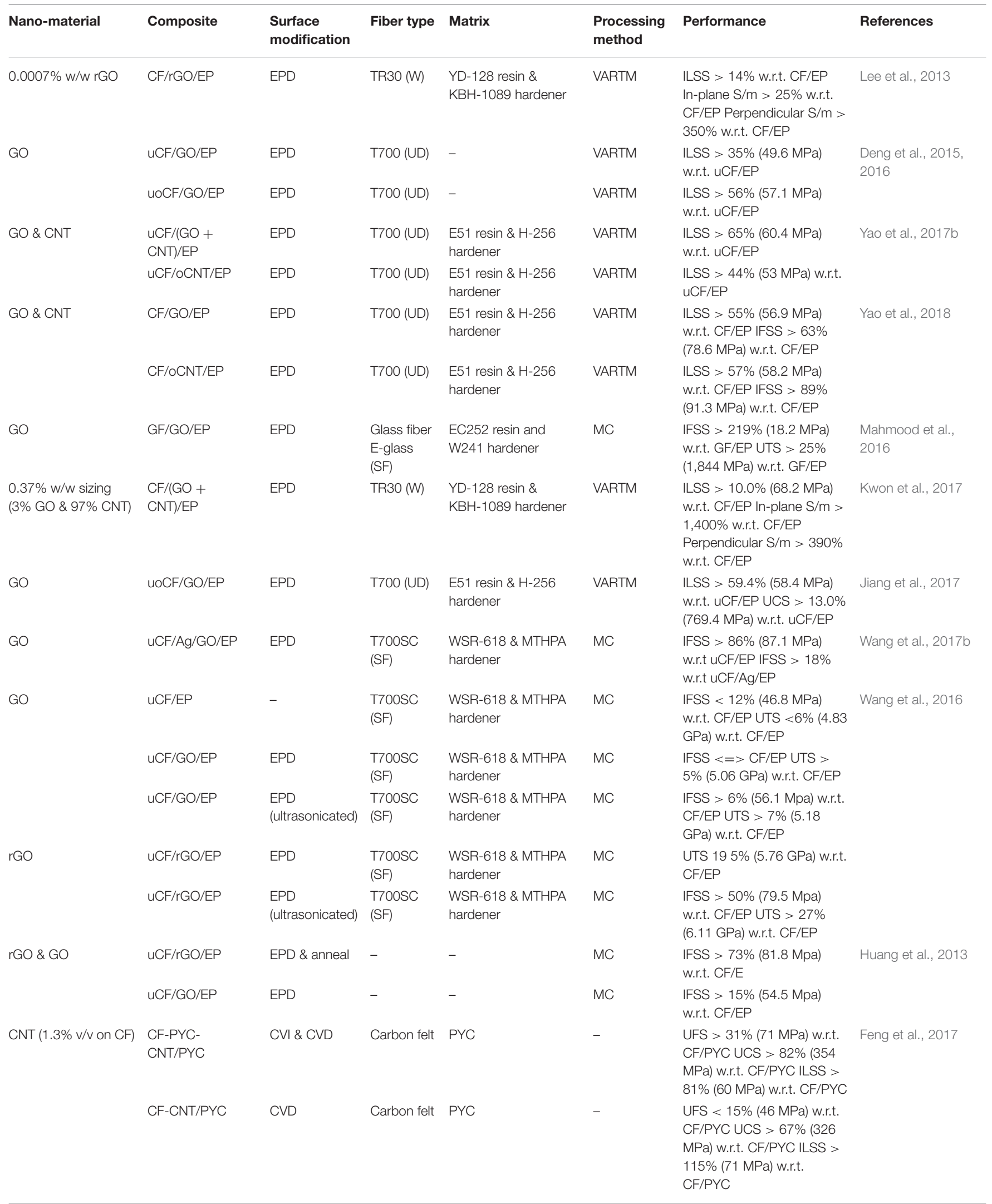


TABLE 2 | Continued

\begin{tabular}{|c|c|c|c|c|c|c|c|}
\hline Nano-material & Composite & $\begin{array}{l}\text { Surface } \\
\text { modification }\end{array}$ & Fiber type & Matrix & $\begin{array}{l}\text { Processing } \\
\text { method }\end{array}$ & Performance & References \\
\hline $\begin{array}{l}\text { CNT }(0.28 \% \text { w/w on } \\
\text { CF) }\end{array}$ & uCF/oCNT/EP & $\begin{array}{l}\text { EPD } \\
\text { (ultrasonicated) }\end{array}$ & T700 (UD) & $\begin{array}{l}\text { JC-02A resin, } \\
\text { JH-0511 accelerator \& } \\
\text { THPA hardener }\end{array}$ & Hot press & $\begin{array}{l}\text { UFS > 9.46\% (997.7 MPa) } \\
\text { w.r.t. CF/EP G(flex) > 15.4\% } \\
(69.5 \mathrm{MPa}) \text { w.r.t. CF/EP } \\
\text { ILSS > } 11 \%(88.3 \mathrm{MPa}) \\
\text { w.r.t. CF/EP IFSS > 33\% } \\
\text { (72 MPa) w.r.t. CF/EP }\end{array}$ & Sui et al., 2017 \\
\hline CNT & $\begin{array}{l}\text { uoCF } /(0.15 \% \mathrm{w} / \mathrm{w} \\
\text { oCNT sizing }) / \mathrm{EP}\end{array}$ & EPD & T700 & $\begin{array}{l}\text { JC-02A resin, } \\
\text { JH-0511 accelerator \& } \\
\text { THPA hardener }\end{array}$ & VARTM & $\begin{array}{l}\text { UTS }>24 \%(46 \mathrm{MPa}) \text { w.r.t. } \\
\text { CF/EP UFS }>18 \%(1,079 \\
\text { MPa) w.r.t. CF/EP ILSS }> \\
15 \%(80.8 \mathrm{MPa}) \text { w.r.t. } \\
\text { CF/EP IFSS > } 45 \%(69.6 \\
\text { MPa) w.r.t. CF/EP T } \mathrm{g}>2^{\circ} \mathrm{C} \\
\left(130^{\circ} \mathrm{C}\right) \text { w.r.t. EP }\end{array}$ & Zhao et al., 2017 \\
\hline GO & uCF/GO/EP & EPD & $\begin{array}{l}\text { T700SC } \\
\text { (SF) }\end{array}$ & $\begin{array}{l}\text { Epoxy resin \& TETA } \\
\text { hardener }\end{array}$ & $\begin{array}{l}\text { Pelletised } \\
\text { and cast } \\
\text { mold }\end{array}$ & $\begin{array}{l}\text { Conductivity }>216 \%(6.57 \\
\text { S/m) w.r.t. uCF/EP }\end{array}$ & Wu et al., 2016 \\
\hline \multirow[t]{2}{*}{$\mathrm{GO} \& \mathrm{rGO}$} & uCF/GO/EP & EPD & $\begin{array}{l}\text { T700SC } \\
\text { (SF) }\end{array}$ & Polyester & $\begin{array}{l}\text { Pelletised } \\
\text { and cast } \\
\text { mold }\end{array}$ & $\begin{array}{l}\text { Conductivity }>\sim 29 \%(\sim 5.8 \\
\text { S/m) w.r.t. uCF/EP }\end{array}$ & Chen et al., 2016 \\
\hline & uCF/rGO/EP & EPD & $\begin{array}{l}\text { T700SC } \\
\text { (SF) }\end{array}$ & Polyester & $\begin{array}{l}\text { Pelletised } \\
\text { and cast } \\
\text { mold }\end{array}$ & $\begin{array}{l}\text { Conductivity }>58 \%(7.13 \\
\text { S/m) w.r.t. UCF/EP }\end{array}$ & \\
\hline
\end{tabular}

Mpa, respectively (Yao et al., 2018). Earlier work by the team (Deng et al., 2015, 2016) proved that oxidizing the carbon fiber in $\mathrm{H}_{2} \mathrm{O}_{2}$ and $\mathrm{HNO}_{3}$ added hydroxyl and carboxyl functional groups to the fiber surface and this was concluded from FTIR results and by observing a reduction in contact angle using water and glycol. GO was synthesized by Hummers method and added to the carbon fiber surface by EPD. FTIR, wettability, AFM and SEM showed the presence of GO on the carbon fiber surface and demonstrated that the modification had increase roughness and surface energy; which favorably improved interfacial mechanical properties. Composite single fiber samples were made using E51 bisphenol-A based resin and H-256 amine hardener and mechanically tested with best results from desized and oxidized carbon fiber with GO deposited on the surface.

Additionally, it was suggested that GO may react covalently during the epoxy curing reaction however no analysis was performed to prove this. Following the same procedure, one study (Yao et al., 2018) compared the performance of CNT to GO with best performance demonstrated by CNT. The work was also up-scaled during the experiments from single fiber to multi-fiber applications showing a potential engineering application. The work concluded that the improvement in CNT performance was due to difference in structure between one dimensional CNT and two-dimensional GO. The CNT increase surface roughness more than GO therefore there is a higher contact area between fiber and matrix which improves mechanical properties. Although GO also increases roughness, it can also act as a steric hindrance due to the flat planar structure which can block contact between the fiber and matrix. These conclusions were supported by moisture absorption tests which were used to qualitatively assess matrix to fiber adhesion and composite porosity. GO modified composites showed the lowest level of moisture absorption compared to $\mathrm{CNT}$ and this was due to the layer-by-layer structure compared to the one-dimensional CNT. SEM inspection of the fracture surface showed evidence of a matrix cohesion failure rather than adhesion; proving that both GO and CNT surface modifications were successful.

Novel work (Wang et al., 2017b) modified the carbon fiber by first adding silver nanoparticles through electrophoresis in solution of PVP containing $\mathrm{AgNO}_{3}$. GO was produced by a modified Hummers method and added to the CF-Ag surface by EPD. The surface treatment with Ag and then GO was shown to progressively decrease contact angle and increase surface energy. Composited were made using droplets of bisphenol-A based WSR-618 epoxy resin and H-8390 hardener. Mechanical testing demonstrated that the IFSS had increased by $86 \%$ from 47 to 87 $\mathrm{MPa}$. Tensile strength improved by $37 \%$ from 4.54 to $6.21 \mathrm{GPa}$. TEM analysis of CF-Ag showed spherical particles $30-70 \mathrm{~nm}$ in diameter on the surface of the fiber and these are said to be silver; supported by FTIR and XPS. After GO was added, Raman, FTIR and XPS showed the change in surface crystalline structure and chemical composition. SEM and TEM showed a rougher surface and concluded that the intermolecular forces of attraction between the carbon fiber and GO macromolecule acted to anchor the Ag nanoparticles in place to create a unique hierarchical structure. The improved performance of the CF/Ag/GO/epoxy composite was concluded to be from silver nanoparticles acting as filler to plug fiber surface defects and reinforce the fiber. This effect was complimented with the addition of GO which acted to reinforce the interface. This technique showed an improvement in mechanical properties when compared to the earlier reported work (Deng et al., 2015, 2016; Yao et al., 2018) performed 
however for comparison reasons it would have been beneficial for the group (Wang et al., 2017b) to have prepared a control sample of CF/GO/epoxy to quantify the effect that silver omission.

The highest improvement in mechanical performance was achieved with GO modified glass fiber via EPD which achieved an improvement in IFSS of $219 \%$ from 6 to $18 \mathrm{MPa}$ (Mahmood et al., 2016). Ultimate tensile strength also increased after fiber surface medication with a $25 \%$ improvement from 1.46 to 1.84 GPa. In this work glass fiber was supplied complete with sizing suitable for creating composites with epoxy; and unlike most other work the sizing was not removed. Specific micro tests were performed on the GF/GO interface and found that delamination occurred with at shear force of $0.13 \mathrm{GPa}$ compared to $18 \mathrm{MPa}$ for single fiber fragmentation tests which suggests that the adhesive forces between GO and GF are greater than GO and epoxy. This is an interesting test which would be useful for further characterization of the interface properties of carbon fiber/epoxy composites. Although glass fiber is not the subject of this review, it is important to highlight the potential effect that sizing has, considering that this work (Mahmood et al., 2016) has shown the greatest improvement in IFSS. Carbon fiber sizing is a surface treatment which is often proprietary and commercially sensitive. Performance of the as supplied materials (i.e., sized fiber and epoxy) should also be incorporated in to control experiments in addition to analysis of un-sized fibers and epoxy. This is applicable to all methods of fiber surface modification.

\section{Dipping and Spraying}

The dipping and spraying techniques are the most simplistic methods discussed herein and involves either immersing fibers in a solution to nanoparticles or spraying the fibers with the solution. By these means the fiber surface becomes activated with nanoparticles. Table 3 shows recent advances in this area and reported improvements in properties.

A dipping technique was reported (Chen et al., 2014) to modify the surface of carbon with functionalised GO. The Marcano method was employed to synthesize highly oxidized GO which was subsequently reacted with silanol of silane coupling agent $\mathrm{KH}-550$ it was proposed that silanol became covalently linked to GO by reacting with hydroxyl and epoxy groups. Covalent linkages between hydroxide and silanol of silane coupling agent by hydrolysis; and the epoxy groups could form peptide bonds with the amino groups of the coupling agent. This theory was supported with dispersion tests showing that the surface chemistry had changed whereby silanised GO (S-GO) was found to have settled in an aqueous medium unlike GO and furthermore, the solubility in acetone improved. Additional FTIR showed new peaks in S-GO at 2,930 and 2,850 $\mathrm{cm}^{-1}$ from the asymmetric vibration of the $-\mathrm{CH}_{2}$ - present in the alkyl chains of $\mathrm{t}$ silane moieties. Additional bands at $936,1,059$, and $3,300 \mathrm{~cm}^{-1}$ showed presence of $\mathrm{Si}-\mathrm{O}-\mathrm{C}, \mathrm{Si}-\mathrm{O}-\mathrm{Si}$ groups and $\mathrm{N}-\mathrm{H}$ vibration. XPS spectra analysis supported these conclusions showing that hydroxyl and epoxy group content of GO had reduced after the reaction and that silicon and nitrogen content had increased.

Carbon fibers were desized in acetone and petroleum ether [95]. GO and S-GO were dispersed in water and acetone, respectively, and carbon fiber was dipped to modify the surface.
Composite samples were made with bisphenol-A based HS5832 resin and tetrahydrophthalic anhydride hardener and mechanical testing of sized, un-sized and GO, S-GO modified fibers were performed and achieved IFSS of $65 \mathrm{MPa}$ for $0.5 \% \mathrm{w} / \mathrm{w} \mathrm{S}-\mathrm{GO}$ compared to 46 and $40 \mathrm{MPa}$ for sized and un-sized carbon fibers. Interestingly fibers functionalised with GO only showed the lowest IFSS of $32 \mathrm{MPa}$. Similar trends were observed in ILSS, flexural strength and flexural modulus. Tensile strength was observed to improve from 1,340 MPa for base composites to 1,540 MPa for those containing S-GO. Once again, GO modified fiber composites showed a reduction in UTS to $1,150 \mathrm{MPa}$. Elastic modulus was $34.5,40.5$, and $48.7 \mathrm{GPa}$ for S-GO, base composites and GO, respectively. The researchers proposed that the presence of GO reduced wettability through over aggregation and SEM supports this assessment where the fiber surface appears to be overloaded with GO compared to S-GO. Considering that van der Waals forces of attraction exist between GO and fiber surface then an overloaded fiber surface with GO could weaken the interface. It was suggested that silane in S-GO would have participated in the curing reaction which contributed to the improved mechanical properties. The S-GO chemical properties also allowed for a better dispersion and interaction with the epoxy resin. Further supporting the synergistic effects was analysis of the gradient interphase stiffness that showed a linear transition of stiffness from fiber to epoxy. This allow loading to be uniformly transferred from matrix to fiber with the S-GO dampening the otherwise steep transition that is normally observed to improve interface and mechanical performance. The poor performance of GO was in contradiction to the work that used EPD to deposit $\mathrm{GO}$ on fiber surface. This reason for this is unclear; the work (Chen et al., 2014) used 0.5\% w/w GO whereas the EPD work did not specify the weight loading. Potentially had GO been loaded at a reduced concentration then improved mechanical performance may have been achievable.

In variant dipping method was employed (Zhang et al., 2012) to size carbon fiber with a solution of epoxy and 5\% w/w GO. Treatment of carbon fiber improved IFSS by $35.0 \%$ from 72 to $97 \mathrm{MPa}$ in comparison to commercially available sized carbon fibers. Ultimate tensile strength (UTS) improved by $34 \%$ from 1.5 to $1.9 \mathrm{GPa}$ and tensile modulus improved by $23 \%$ from 42 to $52 \mathrm{GPa}$. Inspection of the fracture surface by SEM showed that there was minimal fiber pull-out after fibers were treated with GO sizing which shows than the nanofiller acted as a barrier to crack propagation in the interface. This work demonstrated that it is possible to improve interface mechanical properties compared to untreated commercially available products. The researchers cited that improved wettability and better intermolecular interactions at the interface improved mechanical properties (Zhang et al., 2012).

A spraying technique was used (Rodríguez-González et al., 2018) to modify the surface of carbon fiber pre-pregs with CNT and GO was produced by a modified Hummers method. Both GO and multi-walled CNT were separately mixed in ethanol and sprayed between pre-preg layers at a content of $0.25 \% \mathrm{w} / \mathrm{w}$. FTIR and Ramen showed a change in surface chemistry and crystalline structure depending on which treatment had been performed. An artificial crack was introduced during lay-up by inserting a Teflon 
TABLE 3 | A summary of results from literature investigating dipping and spraying methods to modify the fiber surface properties.

\begin{tabular}{|c|c|c|c|c|c|c|c|}
\hline Nano-material & Composite & $\begin{array}{l}\text { Surface } \\
\text { modification }\end{array}$ & Fiber type & Matrix & $\begin{array}{l}\text { Processing } \\
\text { method }\end{array}$ & Performance & References \\
\hline $\begin{array}{l}5 \% \text { w/w GO in sizing } \\
\text { solution }\end{array}$ & uCF/GO/EP & Dipping & $\begin{array}{l}\text { T700S } \\
\text { (UD) }\end{array}$ & $\begin{array}{l}\text { 60: } 40 \text { E20 \& E54; } \\
\text { DDM, DDS \& 2-ethyl- } \\
\text { 4-methylimidazole } \\
\text { hardener }\end{array}$ & Pre-preg \& VAC & $\begin{array}{l}\text { IFSS > 69.3\% ( } 97.2 \mathrm{MPa}) \\
\text { w.r.t. UCF/EP IFSS > 35\% } \\
\text { w.r.t. CF/EP ILSS > } 12 \% \\
\text { (51.3 MPa) w.r.t. CF/EP UTS } \\
>34 \%(1,942.1 \mathrm{MPa}) \text { w.r.t. } \\
\text { CF/EP G(tens) > 23\% (52.1 } \\
\text { GPa) w.r.t. CF/EP }\end{array}$ & Zhang et al., 2012 \\
\hline $\begin{array}{l}0.25 \% \text { w/w GNP on } \\
\text { fiber }\end{array}$ & GF/GNP/EP & Dipping & $\begin{array}{l}\text { S2 glass } \\
\text { fiber (W) }\end{array}$ & $\begin{array}{l}\text { SC- } 15 \text { resin \& SC-15 } \\
\text { hardener }\end{array}$ & VARTM & $\begin{array}{l}\text { UFS > 29\% (419 MPa) w.r.t. } \\
\text { GF/EP }\end{array}$ & Kamar et al., 2015 \\
\hline $\begin{array}{l}3 \% \text { GNP + NMP + } \\
\text { Epon-828 + mPDA } \\
\text { sizing }\end{array}$ & $\begin{array}{l}\text { uoCF/GNP + } \\
\text { EP/EP }\end{array}$ & Dipping & AS4 (UD) & $\begin{array}{l}\text { Epon-828 resin \& } \\
\text { mPDA hardener }\end{array}$ & VARTM & $\begin{array}{l}\text { UFS }>82 \% \text { w.r.t. uoCF/EP } \\
\text { UFS }>51 \% \text { w.r.t. uoCF/EP } \\
\text { (sizing)/EP ILSS > 19\% } \\
\text { w.r.t. uoCF/EP UTS > } 7 \% \\
\text { w.r.t. uoCF/EP } \\
\text { Perpendicular S/m > 165\% } \\
\text { w.r.t. uoCF/E }\end{array}$ & Qin et al., 2015 \\
\hline $\begin{array}{l}0.5 \% \text { w/w S-GO on } \\
\text { fiber }\end{array}$ & uCF/S-GO/EP & Dipping & T700 (UD) & $\begin{array}{l}\text { HS5382 resin \& } \\
\text { etrahydrophthalicanhydri } \\
\text { hardener }\end{array}$ & $\begin{array}{l}\text { VARTM } \\
\text { ride }\end{array}$ & $\begin{array}{l}\text { IFSS }>42 \%(64.8 \mathrm{MPa}) \\
\text { w.r.t. CF/EP ILSS > 11\% } \\
(83.5 \mathrm{MPa}) \text { w.r.t. CF/EP UTS } \\
>15 \%(1,543 \mathrm{MPa}) \text { w.r.t. } \\
\text { uCF/EP G(tens) > 20\% } \\
(48.7 \mathrm{MPa}) \text { w.r.t. uCF/EP } \\
\text { UFS > 16\% (1,160 MPa) } \\
\text { w.r.t. uCF/EP G(flex) > 15\% } \\
\text { (82 GPa) w.r.t. UCF/EP }\end{array}$ & Chen et al., 2014 \\
\hline TEGO (rGO) & $\begin{array}{l}(\mathrm{CF}+0.01 \% \mathrm{w} / \mathrm{w} \\
\mathrm{TEGO} /(\mathrm{EP}+ \\
0.01 \% \mathrm{w} / \mathrm{w} \text { TEGO) }\end{array}$ & $\begin{array}{l}\text { Spray on CF } \\
\text { \& blend in } \\
\text { matrix } \\
\text { (hybrid) }\end{array}$ & $\begin{array}{l}{\left[90 / 0^{\circ}\right]:} \\
310 \mathrm{~g} / \mathrm{m}^{2} \\
\mathrm{CF}(\mathrm{UD}) \times \\
10 \mathrm{~g} / \mathrm{m}^{2} \\
\text { GF (UD) }\end{array}$ & - & VARTM & $\begin{array}{l}\text { S > 240\% (102 S/cm) w.r.t. } \\
\text { CF/EP UFS > 51\% w.r.t. } \\
\text { CF/EP G(flex) > 31\% w.r.t. } \\
\text { CF/EP UTS > 19\% w.r.t. } \\
\text { CF/EP G(tens) > 20\% w.r.t. } \\
\text { CF/EP Impact strength > } \\
30 \% \text { w.r.t. CF/EP }\end{array}$ & $\begin{array}{l}\text { Zanjani et al., 2016, } \\
2018\end{array}$ \\
\hline GO & $\begin{array}{l}\text { uoCF-COOH/GO- } \\
\mathrm{NH}_{2} / \mathrm{PEEK}\end{array}$ & $\begin{array}{l}\text { Dipping } \\
\text { (zwitterionic) }\end{array}$ & T300 (SF) & PEEK powder & Hot press & $\begin{array}{l}\text { UFS > 20\% (905 MPa) w.r.t } \\
\text { uCF/PEEK G(flex) }>14 \% \\
(65 \mathrm{GPa}) \text { w.r.t uCF/PEEK } \\
\text { ILSS > } 12 \%(84.5 \mathrm{MPa}) \\
\text { w.r.t uCF/PEEK IFSS > 36\% } \\
\text { (62.5 MPa) w.r.t UCF/PEEK }\end{array}$ & \\
\hline \multirow[t]{2}{*}{ GO } & UCF-PDA/GO/EP & Spray & T300 (W) & $\begin{array}{l}\text { Epolam } 5015 \text { resin } \\
\text { and hardener }\end{array}$ & WLU & $\begin{array}{l}\mathrm{G}_{(I C)}<=>C F / E P \text { Stable } \\
\text { crack propagation }\end{array}$ & Wang et al., 2017d \\
\hline & uCF-PDA/GO/EP & Spray & Т300 (W) & $\begin{array}{l}\text { XB } 9721 \text { and } \\
\text { anhydride Aradur } 917 \\
\text { hardener }\end{array}$ & WLU & $G_{(I C)}>11.7 \%$ w.r.t. CF/EP & \\
\hline \multirow[t]{3}{*}{ CNT \& GO } & $\begin{array}{l}\mathrm{CF} /(0.25 \% \mathrm{w} / \mathrm{w} \\
\mathrm{GO} / \mathrm{EP}\end{array}$ & Spray & UD & $\begin{array}{l}\text { DA 409U/G35 } 150 \\
\text { pre-preg system }\end{array}$ & Pre-preg \& VAC & $\begin{array}{l}\text { ILSS }>3 \%(74.4 \mathrm{MPa}) \text { w.r.t. } \\
\mathrm{CF} / \mathrm{EP} \mathrm{G}_{(\mathrm{IC})}>8 \%(596.6 \mathrm{~J} \\
\left./ \mathrm{m}^{2}\right) \text { w.r.t. CF/EP }\end{array}$ & $\begin{array}{l}\text { Rodríguez-González } \\
\text { et al., } 2018\end{array}$ \\
\hline & $\begin{array}{l}\mathrm{CF} /(0.25 \% \mathrm{w} / \mathrm{w} \\
\mathrm{CNT}) / \mathrm{EP}\end{array}$ & Spray & UD & $\begin{array}{l}\text { DA 409U/G35 } 150 \\
\text { pre-preg system }\end{array}$ & Pre-preg \& VAC & $\begin{array}{l}\text { ILSS }>3 \%(74.7 \mathrm{MPa}) \text { w.r.t. } \\
\mathrm{CF} / \mathrm{EP} \mathrm{G}_{(\mathrm{IC})}>12 \%(615.4 \mathrm{~J} \\
\left./ \mathrm{m}^{2}\right) \text { w.r.t. CF/EP }\end{array}$ & \\
\hline & $\begin{array}{l}\mathrm{CF} /(0.25 \% \mathrm{w} / \mathrm{w} \\
66 \% \mathrm{GO}+33 \% \\
\mathrm{CNT}) / \mathrm{EP}\end{array}$ & Spray & UD & $\begin{array}{l}\text { DA 409U/G35 } 150 \\
\text { pre-preg system }\end{array}$ & Pre-preg \& VAC & $\begin{array}{l}\text { ILSS }>5 \%(75.6 \mathrm{MPa}) \text { w.r.t. } \\
\mathrm{CF} / \mathrm{EP} \mathrm{G}_{(\mathrm{IC})}>17 \%(644.1 \mathrm{~J} \\
\left./ \mathrm{m}^{2}\right) \text { w.r.t. CF/EP }\end{array}$ & \\
\hline
\end{tabular}


film. A hybrid sample of GO and CNT was also prepared at $0.25 \%$ w/w made up of 1:2 w/w ratio of GO:CNT. End notched flexural testing was performed to assess crack propagation and the hybrid composite performed best with an improvement of $17 \%$ in GIC from 550 to $644 \mathrm{~J} / \mathrm{m}^{2}$. ILSS was also best for the hybrid with $5 \%$ increase from 72.0 to $75.6 \mathrm{MPa}$. The researchers concluded that the presence of a three-dimensional CNT and GO surface structure increased the surface roughness between pre-pregs improving interface properties. In addition, they demonstrated that a mixture of hydrophobic (CNT) and hydrophilic (GO) nanofiller can improve compatibility of carbon nanostructures with epoxy as an additional reason for the interface results. The research work shows that there are additional novel methods to incorporate GO and other graphene-based nanomaterials in to composite materials to improve mechanical properties.

A different method introduced thermally exfoliated GO (TEGO) to the fiber surface and matrix to investigate the benefits of multi-scale modification and the multiscale modification demonstrated a good improvement in overall properties (Zanjani et al., 2016, 2018). TEGO was 23 layers thick with an $\sim 4 \%$ oxygen content and therefore relatively graphitic compared to GO produced by Hummers method. TEGO was dispersed in to the composite in three ways; firstly, TEGO was dispersed on to the carbon fiber surface by electro-spraying and secondly TEGO was mixed directly with epoxy hardener and dispersed by sonication. The third method combined the fiber and matrix modifications to create a multi-scale composite $(0.01 \% \mathrm{w} / \mathrm{w}$ TEGO on the fiber and mixed in to the hardener). Flexural strength increased by $51 \%$ from 730 to $1,104 \mathrm{MPa}$ and flexural modulus increased by $31 \%$ to $97 \mathrm{GPa}$, UTS increased by $19 \%$ from to $0.8 \mathrm{GPa}$ and tensile modulus increased by $20 \% 23 \mathrm{GPa}$ while impact strength improved by $30 \%$. Electrical conductivity was also shown to increase by $240 \%$ from 30 to $102 \mathrm{~S} / \mathrm{cm}$. The fracture surfaces from flexural testing on unmodified CFRC showed clear indications of delamination. In samples where the fiber only was treated with TEGO there was negligible delamination showing a stronger matrix to fiber interface. For samples where only the matrix was modified delamination was observed however this occurred at a higher flexural load due to the reinforcement of the matrix with TEGO. The hybrid sample failed at a much higher load and showed predominantly matrix cracking fiber failure however their minor fiber pull-out was also observed but not full delamination. This work was performed on fiber fabrics on a demonstrating that multi-scale modification is practically possible in a larger laboratory environment and this technique offers a real improvement in properties. The modification techniques were simple however these techniques can be modified to include covalent modification and tailored to application specific requirements.

A range of surface modification techniques including dipping and covalent bonding was shown (Liu et al., 2018) to improve mechanical properties as illustrated in Figure 3. In all cases low modulus carbon fibers were treated with acetone to de-size. Experiments were setup to test the different intermolecular attractive forces between carbon fiber and GO based surface modification. Composites were made using PEEK and mechanical testing was performed. The first set of experiments tested van der Walls forces by dipping carbon fiber in to a $\mathrm{GO}(\mathrm{aq})$ solution. Mechanical testing showed that IFSS and flexural modulus increased by $26 \%$ to $58 \mathrm{MPa}$ and $5 \%$ to $60 \mathrm{GPa}$, respectively. The second piece of work tested ionic forces of attraction by first oxidizing carbon fiber in $\mathrm{H}_{2} \mathrm{SO}_{4}$ and $\mathrm{HNO}_{3}$ to make CF-COOH. Separately GO was functionalised with primary amine by reacting with APTES to make GO- $\mathrm{NH}_{2}$. CF-COOH and GO-NH $\mathrm{N}_{2}$ were then mixed in solution to allow a zwitterionic network to set-up between the constituents (CF-COO ${ }^{-} \mathrm{H}_{3} \mathrm{~N}^{+}-\mathrm{GO}$ ). Mechanical testing showed that IFSS and flexural modulus had increased by $36 \%$ to 63 $\mathrm{MPa}$ and $14 \%$ to $65 \mathrm{GPa}$, respectively. The third experiment tested covalent bonding performance whereby $\mathrm{CF}-\mathrm{COOH}$ was further reacted in $\mathrm{SOCl}_{2}$ to make $\mathrm{CF}-\mathrm{COCl}$. This was reacted with GO-NH $\mathrm{N}_{2}$ to create a peptide bond between GO and CF. Mechanical testing showed that IFSS and flexural modulus had increased by $51 \%$ to $69 \mathrm{MPa}$ and $25 \%$ to $71 \mathrm{GPa}$, respectively. The hierarchical performance was also seen in wettability characterization whereby lowest contact angles and highest surface energies were measured for the covalent bonding of GO to CF. Analysis of fractures by SEM also illustrated this with less fiber full out for the covalent linkage demonstrating a more robust interface. This work is an excellent example of showing how mechanical performance can improve depending on modification technique, however it also validates that for engineering applications a compromise between properties and complexity (i.e., unit operations and processability) may be required.

\section{GO/EPOXY RESIN MATRIX}

The epoxy resin is a type of polymer characterized often with one or more epoxide functional group with at least one of the epoxide functional group acting as a monomer and terminal unit of the polymer within the structural chain. Epoxy resins are extensively used in the production of lightweight carbon fiberreinforced composites (CRFP) to deliver desired engineering properties such as high modulus and strength, low creep, superb chemical and thermal stability (Pielichowski and Njuguna, 2005; Njuguna, 2016). The epoxy/carbon fiber-reinforced composite design, just like any other composite, is heavily dependent on the mechanical and thermal properties of the resulting composites of the manufactured epoxy/carbon fiber-reinforced composite withstanding the conditions set by its application requirements.

Matrix modification is a viable technique for improving mechanical and/or other properties. Table 4 shows recent advances in this area and reported improvements in properties.

Interactions between filler and matrix can be covalent or via weaker attractive forces such as van der Waals. Epoxy has viscosity that is several orders of magnitude greater than water which has a dynamic viscosity of $1 \mathrm{mPa} . s$ at $20^{\circ} \mathrm{C}$. For instance, a typical bisphenol-A based epoxy YD-128 has a dynamic viscosity of $11,500-13,500 \mathrm{MPa} . \mathrm{s}$ at $25^{\circ} \mathrm{C}$ (Kukdo, 2001) whereas the lower viscosity epoxy resins available on the market such as example Eposir-7127 which is a variant of DEGBA epoxy has reported dynamic viscosity of $8,000-10,000 \mathrm{MPa} . \mathrm{s}$ at $20^{\circ} \mathrm{C}$ (SIR 
TABLE 4 | A summary of results from literature investigating the impact of resin matrix modifications on the properties of fiber-reinforced composites.

\begin{tabular}{|c|c|c|c|c|c|c|c|}
\hline Nano-material & Composite & $\begin{array}{l}\text { Surface } \\
\text { modification }\end{array}$ & Fiber type & Matrix & $\begin{array}{l}\text { Processing } \\
\text { method }\end{array}$ & Performance & References \\
\hline $\begin{array}{l}0.3 \% \mathrm{w} / \mathrm{w} \mathrm{GO} \text { in } \\
\text { matrix }\end{array}$ & CF/GO/EP & $\begin{array}{l}\text { Matrix } \\
\text { modification }\end{array}$ & Т300 & $\begin{array}{l}\text { LY-556 resin \& TETA } \\
\text { hardener }\end{array}$ & Hot press & $\begin{array}{l}\text { UFS > 67\% (710 MPa) w.r.t } \\
\text { CF/EP ILSS > 23\% ( } 40.8 \\
\text { MPa) \% w.r.t. CF/EP G(flex) } \\
>75 \% \text { (35 GPa) w.r.t. } \\
\text { CF/EP }\end{array}$ & Pathak et al., 2016 \\
\hline & $\begin{array}{l}\text { uoCF/(EP + } \\
0.35 \% \text { w/w oCNT) }\end{array}$ & $\begin{array}{l}\text { Matrix } \\
\text { modification }\end{array}$ & $\mathrm{T} 700$ & $\begin{array}{l}\text { JC-02A resin, JH-0511 } \\
\text { accelerator \& THPA } \\
\text { hardener }\end{array}$ & VARTM & $\begin{array}{l}\text { UFS }>10 \%(1,004 \mathrm{MPa}) \\
\text { w.r.t. CF/EP ILSS > 4.8\% } \\
\text { (73.3 MPa) w.r.t. CF/EP } \\
\text { IFSS }>10 \%(52.8 \mathrm{MPa}) \\
\text { w.r.t. CF/EP Tg }>5^{\circ} \mathrm{C} \\
\left(133^{\circ} \mathrm{C}\right) \text { w.r.t. CF/EP }\end{array}$ & Zhao et al., 2017 \\
\hline \multirow[t]{3}{*}{ GO } & $\begin{array}{l}\mathrm{CF} /(0.1 \% \mathrm{w} / \mathrm{w} \mathrm{GO} \\
+\mathrm{EP})\end{array}$ & $\begin{array}{l}\text { Matrix } \\
\text { modification }\end{array}$ & W & $\begin{array}{l}\text { IN2 resin \& } \\
\text { polyoxypropylenediamine }\end{array}$ & VARTM & $\begin{array}{l}\text { UTS }<\sim 18 \%(\sim 500 \mathrm{MPa}) \\
\text { w.r.t. CF/EP UFS }<\sim 13 \% \\
(\sim 560 \mathrm{MPa}) \text { w.r.t. CF/ }\end{array}$ & Watson et al., 2017 \\
\hline & $\begin{array}{l}\mathrm{CF} /(0.3 \% \mathrm{w} / \mathrm{w} \mathrm{GO} \\
+\mathrm{EP})\end{array}$ & $\begin{array}{l}\text { Matrix } \\
\text { modification }\end{array}$ & W & $\begin{array}{l}\text { IN2 resin \& } \\
\text { polyoxypropylenediamine }\end{array}$ & VARTM & $\begin{array}{l}\text { UTS }<\sim 15 \%(\sim 520 \mathrm{MPa}) \\
\text { w.r.t. CF/EP UFS < 23\% } \\
(\sim 490 \mathrm{MPa}) \text { w.r.t. CF/EP }\end{array}$ & \\
\hline & $\begin{array}{l}\mathrm{CF} /(0.5 \% \mathrm{w} / \mathrm{w} \mathrm{GO} \\
+\mathrm{EP})\end{array}$ & $\begin{array}{l}\text { Matrix } \\
\text { modification }\end{array}$ & W & $\begin{array}{l}\text { IN2 resin \& } \\
\text { polyoxypropylenediamine }\end{array}$ & VARTM & $\begin{array}{l}\text { UTS }<\sim 14 \%(\sim 625 \mathrm{MPa}) \\
\text { w.r.t. CF/EP UFS < 19\% } \\
(\sim 520 \mathrm{MPa}) \text { w.r.t. CF/EP }\end{array}$ & \\
\hline $\begin{array}{l}1 \% \mathrm{w} / \mathrm{w} \mathrm{rGO} \text { (in } \\
\text { interleave) }\end{array}$ & $\mathrm{CF} / \mathrm{rGO} / \mathrm{EP}$ & $\begin{array}{l}\text { Matrix } \\
\text { modification } \\
\text { (interleave) }\end{array}$ & $\begin{array}{l}16805 I T L \\
(W)\end{array}$ & $\begin{array}{l}\text { Araldite } F(D G E B A) \& \\
\text { piridine }\end{array}$ & Hot press & $\begin{array}{l}\text { Frac. t'ness }>74 \%(1.3 \\
\left.\mathrm{MPa} / \mathrm{m}^{1 / 2}\right) \text { w.r.t. CF/EP } \\
\text { Frac. energy }>150 \%(0.68 \\
\left.\mathrm{kJ} / \mathrm{m}^{2}\right) \text { w.r.t. CF/EP G(IC) }> \\
145 \%\left(1.30 \mathrm{~kJ} / \mathrm{m}^{2}\right) \text { w.r.t. } \\
\text { CF/EP }\end{array}$ & Du et al., 2017 \\
\hline $0.3 \% \mathrm{w} / \mathrm{w} \mathrm{fCNT}$ in EP & $\mathrm{CF} /(\mathrm{fCNT}+\mathrm{EP})$ & $\begin{array}{l}\text { Matrix } \\
\text { modification } \\
\text { (interleaved) }\end{array}$ & $\begin{array}{l}\text { HTS40 }(\mathrm{W}) \\
\text { \& F13 } \\
\text { sizing }\end{array}$ & Leo 2396 & VARTM & $\begin{array}{l}\text { UCS }>14 \%(\sim 144 \mathrm{MPa}) \\
\mathrm{CF} / \mathrm{EP} \text { (interleaved) Damage } \\
\text { area }<\sim 9 \%\left(\sim 2,450 \mathrm{~mm}^{2}\right) \\
\text { w.r.t. CF/EP (interleaved) } \\
\text { Conductivity }>\sim 45 \% \\
\text { ( 0.77 S/cm) w.r.t. CF/EP } \\
\text { (interleaved) }\end{array}$ & \\
\hline \multirow[t]{2}{*}{ GO \& rGO } & $\begin{array}{l}\mathrm{CF} /(0.1 \% \mathrm{w} / \mathrm{w} \mathrm{GO} \\
+\mathrm{EP})\end{array}$ & $\begin{array}{l}\text { Matrix } \\
\text { modification }\end{array}$ & $\begin{array}{l}\text { CCF300 } \\
\text { (UD) }\end{array}$ & $\begin{array}{l}\text { E54 \& diamino diphenyl } \\
\text { methane resins; \& DDS } \\
\text { hardener }\end{array}$ & $\begin{array}{l}\text { Pre-preg \& } \\
\text { hot-press }\end{array}$ & $\begin{array}{l}\text { ILSS > 11\% }(117.5 \mathrm{MPa}) \\
\text { w.r.t. CF/EP IFSS > 32\% } \\
(79 \mathrm{MPa}) \text { w.r.t. CF/EP Res > } \\
2 \%\left(4.6 \times 10^{-2} \Omega\right) \text { w.r.t. } \\
\text { CF/E }\end{array}$ & Li et al., 2016b \\
\hline & $\begin{array}{l}\mathrm{CF} /(0.1 \% \mathrm{w} / \mathrm{w} \\
\mathrm{rGO}+\mathrm{EP})\end{array}$ & $\begin{array}{l}\text { Matrix } \\
\text { modification }\end{array}$ & $\begin{array}{l}\text { CCF300 } \\
\text { (UD) }\end{array}$ & $\begin{array}{l}\text { E54 \& diamino diphenyl } \\
\text { methane resins; \& DDS } \\
\text { hardener }\end{array}$ & $\begin{array}{l}\text { Pre-preg \& } \\
\text { hot-press }\end{array}$ & $\begin{array}{l}\text { ILSS > } 8 \%(115 \mathrm{MPa}) \text { w.r.t. } \\
\mathrm{CF} / \mathrm{EP} \text { IFSS }>21 \%(72 \\
\mathrm{MPa}) \text { w.r.t. CF/EP Res }<=> \\
\mathrm{CF} / \mathrm{EP}\left(4.5 \times 10^{-2} \Omega\right)\end{array}$ & \\
\hline GO & $\begin{array}{l}\mathrm{CF} /(\mathrm{GO}-\mathrm{DOPO}+ \\
\mathrm{EP})\end{array}$ & $\begin{array}{l}\text { Matrix } \\
\text { modification }\end{array}$ & T700 (W) & $\begin{array}{l}\text { JY-256 resin, DMP-30 } \\
\text { accelerant \& MTHPA } \\
\text { hardener }\end{array}$ & $\begin{array}{l}\text { Pre-preg \& } \\
\text { hot-press }\end{array}$ & $\begin{array}{l}\mathrm{T}\left(\text { de-comp) }>37^{\circ} \mathrm{C}\left(369^{\circ} \mathrm{C}\right)\right. \\
\text { w.r.t. CF/EP De-comp wt } \\
63 \% \text { (w.r.t. } 46 \% \text { for CF/EP) }\end{array}$ & Sun et al., 2016 \\
\hline
\end{tabular}




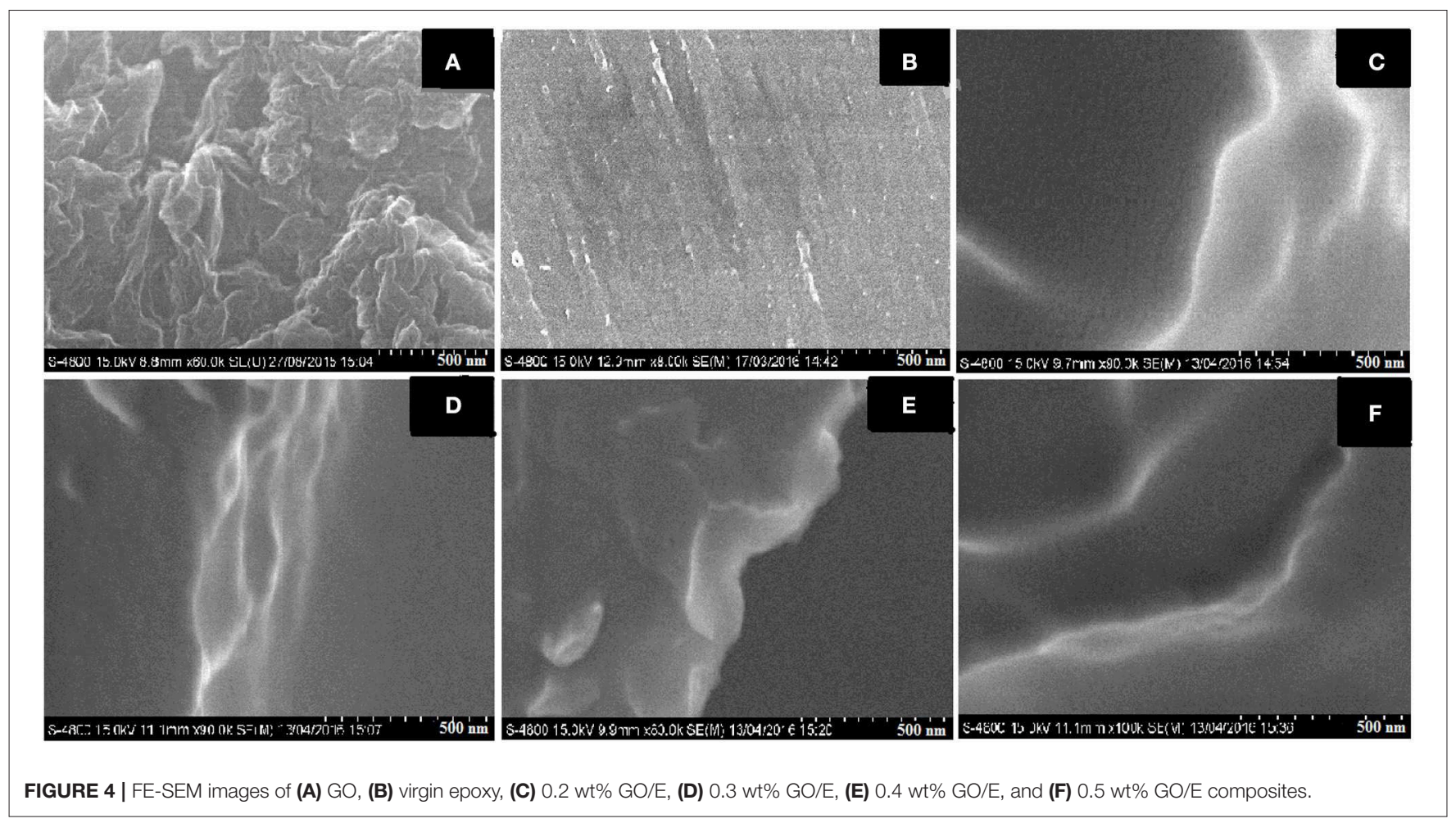

Industriale, 2019). The relatively high viscosity of most epoxy resins has a detrimental effect on achieving good dispersion of nanofiller within the uncured resin. For nanofiller to deliver improved properties a homogeneous dispersion is necessary. Hence, desirable matrix modification techniques are those that provide both favorable matrix/nanofiller chemical interactions and that are dispersible at the nanoscale. Most work within this arena of CFRC research has involved purely mixing of graphene based nanofiller with the matrix; exploration of covalent interaction has generally been the reserve of polymer science.

Paredes et al. (2008) and Konios et al. (2014) conducted similar investigations into the dispersion behavior of GO in various organic solvents. In both studies GO was converted to powder form by grinding small flakes of GO with a mortar and pestle. Their studies were both focused on the solubility of GO, and found that NMP, DMF, THF, distilled water and ethylene glycol all showed good solubility characteristics. It is unlikely that the grinding method used in these studies yielded extremely fine $\mathrm{GO}$, thus potentially reducing the solubility of GO in each of the solvents.

In the literature (Bari et al., 2017) discussed the effects on tensile strengths and elongation of GO/epoxy composites test samples, where the overall tensile strength showed a $30 \mathrm{MPa}$ increase and the elongation of the test specimens showed a $5 \%$ decrease in elongations over the span of the various concentrations of GO concentrations studied. The FESEM images on Figure 4 show the damage characteristics and failure mechanism. A dynamic mechanical analysis of GO/epoxy composites was carried out by Silva et al. (2015) who reported that the Young's modulus of with GO/epoxy composites showed a $50 \%$ increase compared to pristine composites. The results obtained suggest that the presence of isocyanate groups is the key role for achieving good mechanical performance. In particular, the samples prepared with graphene oxide and its reduced form functionalized with isocyanate groups presented better mechanical performance and long-term durability a fact the researchers attributed to the better filler-matrix interactions achieved in theses system.

A reported an improvement of $67 \%$ in flexural strength from 425 to $710 \mathrm{MPa}$ after mixing $0.3 \% \mathrm{w} / \mathrm{w}$ GO in to the matrix was made (Pathak et al., 2016). FTIR and NMR confirmed successful oxidation with the presence of epoxy, hydroxyl and carboxylic acid functional groups. XRD was used to calculate that the layer spacing had increased from 3.35 to $8.71 \AA$ confirming a physical change in the structure. Raman spectroscopy confirmed changes with the G-band shifting from $1,579.53$ to $1,598.83$ $\mathrm{cm}^{-1}$ which indicated that oxidation had disturbed the graphite lattice structure by converting $\mathrm{sp}^{2}$ to $\mathrm{sp}^{3}$ carbon. The D-band gives an indication of defects and this shifted from 1,350.96 to $1,351.01 \mathrm{~cm}^{-1}$ as a result of new oxygen surface moieties on the graphitic basal plane. After oxidation the typical high intensity Raman peaks associated with graphite became more distributed which reflects the disordered nature of GO due to oxidation influencing the crystalline structure. Pre-pregs were made with T-300 fibers and then de-aired in a vacuum oven. The manufactured composites demonstrated improved ILSS by $23 \%$ to $41 \mathrm{MPa}$ and flexural modulus increased by $75 \%$ to $35 \mathrm{GPa}$.

The test samples were prepared using a range of nanofiller content from $00.6 \% \mathrm{w} / \mathrm{w}$ of epoxy and optimal results were 
observed for $0.3 \% \mathrm{w} / \mathrm{w}$. The research group concluded that $0.3 \% \mathrm{w} / \mathrm{w}$ represented the percolation threshold whereby the addition of GO up to $0.3 \% \mathrm{w} / \mathrm{w}$ improved crack deflection and reinforced the composite. At higher concentrations GO tended to agglomerate which had a detrimental effect on mechanical properties. SEM analysis of the fracture surface and in all three examples fiber pull-out is evident therefore this technique does not reinforce the interface as robustly as most carbon fiber surface modifications. The GO nanofiller reinforced the matrix whereby crack propagation was retarded and this effect, combined with the increased rigidity of the composites caused failure to occur almost in the single plane. The TEM showed that after sonication in ethanol GO was relatively well-dispersed and had thickness of a few layers although the agglomeration of GO after dispersion in epoxy was also observed.

This evidence highlights the challenge involved in dispersing GO. SEM shows GO sheets dispersed in ethanol and it is observed that sheets are $2-7 \mu \mathrm{m}$ in size and tend to agglomerate even after dispersion by sonication and the mechanical testing focused purely on interface properties. SEM images showed that GO dispersed in epoxy and further agglomeration was evident. This paper is an excellent example of the challenge that an effective dispersion poses to this technique. It is also telling that flexural mechanical properties only were tested, and no work was performed to characterize tensile properties. Similar work (Watson et al., 2017) using a comparable technique reported that UTS decreased by $15 \%$ from 612 to $520 \mathrm{MPa}$ with a $0.3 \% \mathrm{w} / \mathrm{w}$ loading of GO in epoxy.

Separate work (Li et al., 2016b) used a different technique to combine GO and rGO with epoxy resin in a CFRC. The GO was prepared by a modified Hummers method while rGO was synthesized by reacting GO with hydrazine hydrate; $\mathrm{pH}$ was adjusted to $9-10$ by adding sodium hydroxide which modified the rGO sheets with a charge repulsion effect to prevent excessive agglomeration. In this work the research team identified that rGO tended to agglomerate and took measures to mitigate this effect. Carbon fiber/epoxy/nanofiller composites were prepared with $0.1 \% \mathrm{w} / \mathrm{w}$ GO and $0.1 \% \mathrm{w} / \mathrm{w}$ rGO. Mechanical testing showed that composites containing GO performed slightly better than those with rGO. ILSS and IFSS increased by $11 \%$ (to 118 $\mathrm{MPa}$ ) and $32 \%$ (to $79 \mathrm{MPa}$ ), respectively for GO; whereas the increases were $8 \%$ (to $115 \mathrm{MPa}$ ) and 21\% (72 $\mathrm{MPa}$ ) for ILSS and IFSS, respectively for rGO. In this work GO was prepared by a modified Hummers method. Uni-directional carbon fiber composites were laid-up with CCF300 fibers and cured via a hot-press as illustrated in Figure 5. Atomic force miscroscopy (AFM) was used to measure dispersion of GO and rGO in THF and found a thickness of 1 and $2-3 \mathrm{~nm}$, respectively indicating GO had fully exfoliated in solution. SEM images of the fracture surfaces are shown on Figure 5.

The study showed that composites without nanofiller are shown to fail in Figure 5a by debonding at the surface which demonstrates poor interfacial strength. The other images in Figures 5b-e and mechanical test results demonstrate an improvement in interfacial properties where epoxy adheres to the fiber surface upon failure rather than pulling-out. The addition of excessive nanofiller can act as stress concentrators and crack initiation sites as seen in Figures 5d,e. The researchers proposed that the method of impregnation favored nanofiller to interact with the sizing material on the fibers. It was further suggested that amine congregates in the interphase area with better crosslink density at the interface compared to the bulk polymer as a result of the stoichiometric instability and for this reason the GO was observed to reinforce the interface. It is noteworthy that with rGO the effect is less evident because there is a lower number of oxygen functional groups available to interact favorably with the sizing agent. Additionally, the instability of rGO tends to cause agglomerations and thus at low loading rGO can mechanically impede crack propagation however benefits are quickly lost when nanofiller content is increased. The researchers did not conclude why acetone solution of epoxy was utilized however it is likely that this would have reduced the epoxy resin /hardener viscosity and therefore improved the dispersion of nanofiller within the matrix.

The challenge of dispersion must be overcome if materials engineers are to improve both interface and matrix properties. For this reason, the field of polymer science should be explored for opportunities. There is a field of work within polymer science that has focused on functionalising graphene and graphene derivatives in order to improve nanofiller dispersibility within the matrix. In one reported work (Yao et al., 2017a) GO was prepared by the Hummers method and subsequently reduced in hydrazine hydrate. The rGO was reacted with 4-nitrobenzediazonium salt to add nitrogen dioxide functional groups to the rGO edges. AFM demonstrated a good dispersion of single sheet GO- $\mathrm{NO}_{2}$ in acetone compared to GO while the XRD demonstrated that no subsequent re-stacking had occurred. This worked showed a relatively simple method to improve the dispersion of nanofiller in matrix with UTS increased by $37 \%$ to $71.4 \mathrm{MPa}$. Other novel work (Li et al., 2016a) created an organic/inorganic hybridized GO filler via a complex reaction process whereby GO was first decorated with $\mathrm{Fe}_{3} \mathrm{O}_{4}$ nanoparticles on the basal plane; secondly $\mathrm{GO} / \mathrm{Fe}_{2} \mathrm{O}_{3}$ was reacted with SID-3392 to covalently bond to carboxylic acid and hydroxyl groups. Finally, (GO-SID-3392)/ $\mathrm{Fe}_{2} \mathrm{O}_{3}$ was reacted with potassium salt (PEGS, $\mathrm{C}_{9} \mathrm{H}_{19} \mathrm{C}_{6} \mathrm{H}_{4}\left(\mathrm{OCH}_{2} \mathrm{CH}_{2}\right)_{2} \mathrm{OO}\left(\mathrm{CH}_{2}\right)_{3} \mathrm{SO}_{3}{ }^{-} \mathrm{K}^{+}$) to react covalently with SID-3392 chains to create a liquid crystal molecule (after solvent was removed).

This section demonstrates that simple mixing of graphene based nanofiller with epoxy is not a viable method for improving matrix properties due to challenges of achieving a homogeneous dispersion. Therefore, advancements need to be sought out to improve dispersion. Polymer science potentially offers the most promising opportunities by finding novel means to change the surface chemistry of the nanofiller and thus improve epoxy and nanofiller affinities. Work elsewhere ( $\mathrm{Lu}$ et al., 2018) demonstrated that cure temperature and activation energy reduced after adding CNT to Epon 825 epoxy resin cured with diethyltoluene diamine. This shows the complexity of the challenge and that collaboration between materials scientists and polymer chemists is crucial to developing a full understanding of how graphene derived nanofillers can best be incorporated into the matrix phase. 


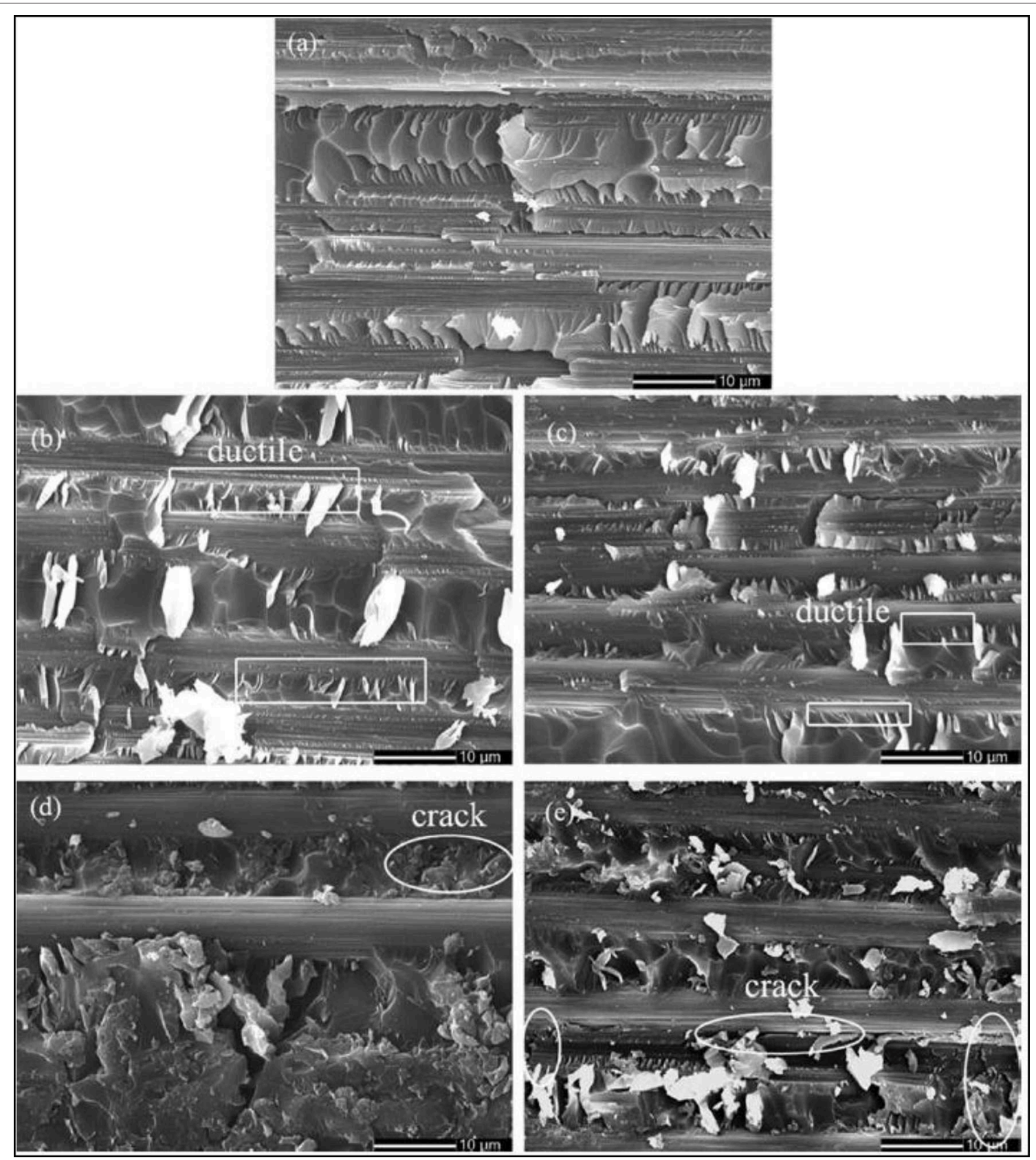

FIGURE 5 | SEM images of fractured surfaces of (a) CF/epoxy composite and (b) CF/epoxy composite with $0.1 \%$ w/w GO, (c) $0.1 \%$ w/w rGO, (d) $0.4 \%$ w/w GO, and (e) $0.4 \%$ w/w rGO. Reproduced from Li et al. (2016b).

Rheology is the study of flow behavior and is generally concerned with fluid materials. Flow is typically measured using shear and shear parameters of stress $\tau$, and strain rate $\varepsilon$; these parameters are calculated form measurements of torque and flow rate. Apparent viscosity or shear stress of the fluid is defined as $\eta$ $=\tau / \varepsilon$. There are however very few studies other than Surnova et al. (2019) based on the rheological properties of epoxies with GO dispersed within. Their results will serve useful as a benchmark of future rheological study. Furthermore, their work shows that as other carbon-based nanomaterials GO also increase the epoxy viscosity as observed elsewhere in the literature (Rafiee et al., 2019).

Surnova et al. (2019) noted a significant increase in epoxy viscosity with as little as $0.4 \mathrm{wt} \% \mathrm{GO}$. This was attributed to a high level of exfoliation of GO in the resin, i.e., the GO as well-dispersed in its solvent. Surnova et al. (2019) also provide evidence that the addition of GO in the resin has a marked increase in the cure time due to the oxidized groups on the 
surface of GO. The oxidized groups act as a catalyst for the ringopening reaction, a reaction which helps polymerise a material, and thus the cure time is reduced. Shear thinning, the decrease of viscosity as shear rate increases can also be observed in Surnova et al. (2019) study. At rest, the GO dispersed in the epoxy exhibits non-Newtonian fluid behavior, which can be associated to the formation of a GO network. As the shear rate increased the GO network is destroyed and the viscosity is reduced.

Rheological testing results showed that the molecule acted like a liquid with viscosity reducing with increasing temperature. Solubility testing showed high affinity with water, toluene and ethanol and it was concluded that the presence of long-chain organic PEGS molecules improve dispersion in epoxy. Mechanical testing showed UTS increased by $60 \%$ from 35 to $65 \mathrm{MPa}$ with $1 \%$ nanofiller and microscopy indicated that no indication of nanofiller agglomeration. The improvement in tensile strength was attributed to improved crack resistance compared to neat epoxy.

It should be also be appreciated that the modification of GO might influence the curing kinetics, which is very important in understanding the impact of modified nanofillers on the performance of hybrid composites. For instance, $\mathrm{Lu}$ et al. (2018) conducted to comparatively investigation on the role of hyperbranched polyester surface modification of CNTs in the cure kinetics of the epoxy resin cured by diethyltoluene diamine (D-EP), D-EP/multi-walled carbon nanotube(D-EP/CNT) composites and D-EP/hyper branched polyester functionalized CNTs (D-EP/CNTs-H20) by nonisothermal differential scanning calorimetry (DSC). Their results revealed that the presence of CNTs shifted the cure temperature to a lower temperature and accelerated the curing of D-EP, and the addition of CNTs-H20 exhibited a stronger effect in accelerating the cure of D-EP.

To sum up, this section demonstrates that direct dispersion of graphene based nanofiller with epoxy resin is currently a limited method for improving matrix properties due to challenges achieving a homogeneous dispersion. Therefore, advancements need to be sought out that can improve dispersion. Polymer science potentially offers the most promising opportunities by finding novel means to change the surface chemistry of the nanofiller and thus improve epoxy and nanofiller affinities.

\section{GRAPHENE /EPOXY CARBON FIBER-REINFORCED COMPOSITES}

The most exciting area of current research is in multi-scale modification of carbon fiber/epoxy composites with graphene based nano materials. Many unique graphene properties have made it an ideal candidate for improving polymer properties of CFRC. The addition of nanofillers into the resin system during composite manufacturing can directly influence the mechanical, thermal and chemical properties of the resulting composite. In turn this increase, e.g., the strength, dimensional properties and hence extend the functional life of the material although graphene nanofillers remain extremely expensive the addition of small amounts is known to improve the mechanical qualities of a composite.

There are many approaches that can be taken to modify the performance of CFRCs. Each technique can be categorized as (1) carbon fiber surface modification or (2) matrix modification; and subcategorised further depending on the chemical processes involved. Carbon fiber surface modifications are specifically targeted at enhancing the fiber/matrix interface properties; and there are generally three approaches viz. (i) dry treatment, (ii) wet-chemical treatment and (iii) multi-scale treatments (Sharma et al., 2014). Matrix modifications are specifically targeted at enhancing the properties of the matrix and/or improving the affinity between matrix and fiber. Typically, this approach involves mixing nanofiller material to the epoxy resin system which will interact covalently or non-covalently (by van der Waals intermolecular forces) with the matrix. The nanofiller can serve a variety of purposes including improved polymer cross-link density; improved mechanical, electrical and/or thermal properties; and/or improved processability (e.g., fine-tuned rheology to improve wettability) (Wei et al., 2015; Atif et al., 2016).

\section{Strength and Stiffness}

It is acknowledged that the addition of graphene oxide (GO) or reduced graphene oxide ( $\mathrm{rGO}$ ), as nanofiller, to a composite material can increase its strength. This is due to its unique ability to fill in micro-cracks as they form within the material. For instance, Bortz et al. (2011) investigated the effect of varying quantities of graphene oxide (GO) on the flexural properties of epoxy/carbon fiber reinforced composites. The study found that the addition of just a small amount (0.1 wt.\%) of GO powder can increase the flexural strength by $25 \%$. However, this improvement is not a linear relationship and the continued addition of GO did not increase the strength in the same fashion. The increases in flexural strength between 0.1 and 1 wt.\% GO was only found to be roughly $5 \%$. This may be due to the GO causing the resin matrix to become brittle and lack of effect fiber-matrix adhesion. Tribological performance of epoxy nanocomposites was conducted by Shen et al., and reported that the wear resistance is significantly enhanced by the addition of GO to epoxy and the specific wear rate is reduced by over $90 \%$ relative to the neat epoxy at $0.5 \mathrm{wt} \%$.GO content. Wan et al. (2014) studied the epoxy composites filled with both graphene oxide (GO) and diglycidyl ether of bisphenol-A functionalized GO (DGEBA-f-GO) sheets. Han et al. (2017) studied GO/epoxy fiber reinforced composites achieved the improvements on interlaminar shear strength (ILSS) attributed to better epoxy resin toughness.

Lian et al. (2014) investigated the multi-walled carbon nanotubes (MWCNTs) by comparing the effect it has on reinforcing a polymer matrix with Kevlar-functionalised graphene nanoribbons (KGNRs). The study was conducted using $0.1,0.3,0.5,0.7,1.0$, and 2.0 wt.\% KGNRs. Once the solution was prepared and $1 \mathrm{~g}$ of the PVC polymer had been added, it was cast onto a glass plate of $120 \times 120 \mathrm{~mm}$. The samples were then cut into strips measuring $60 \times 4 \mathrm{~mm}$ and a tensile load of $6 \mathrm{~mm} / \mathrm{min}$ was applied. Interestingly, the 


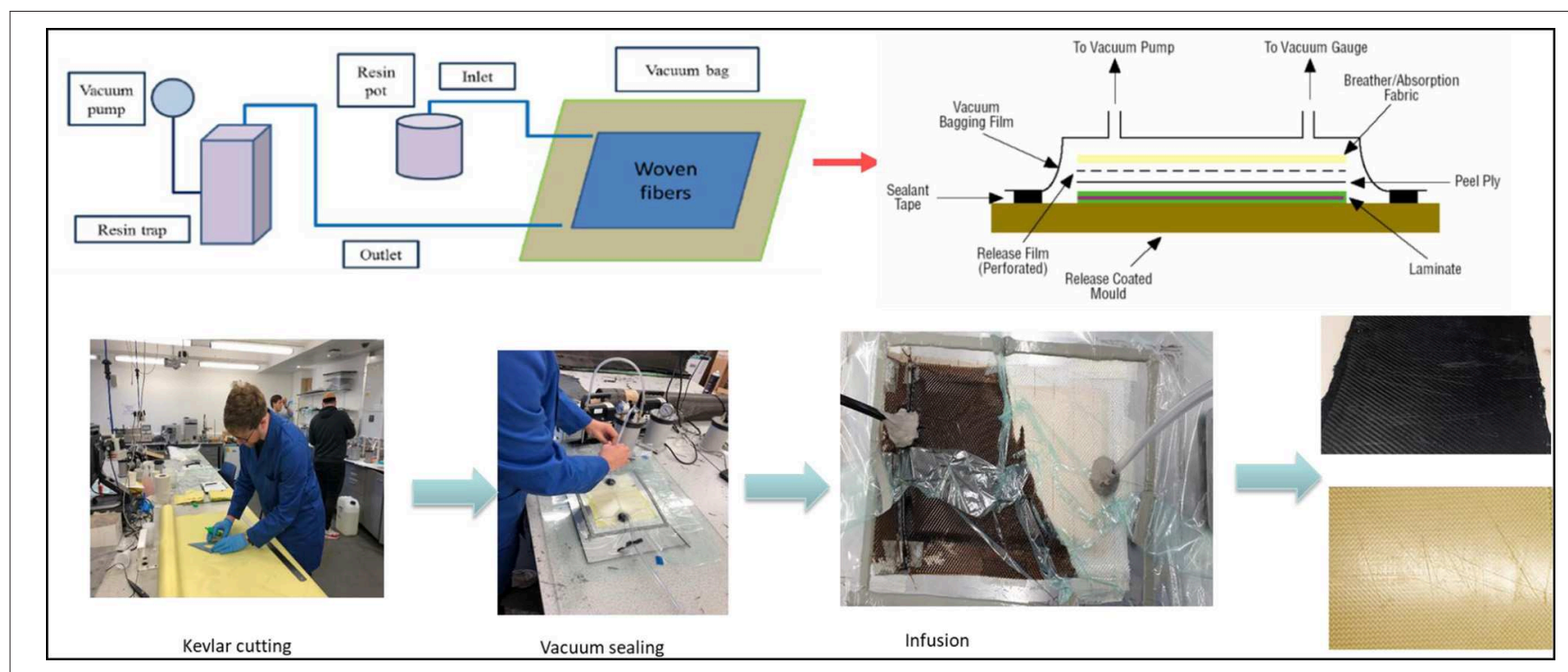

FIGURE 6 | Illustration of composite construction process utilizing GO as nanofiller.

researchers found out that the yield strength of all panels with graphene increased but decreased beyond $0.4 \mathrm{wt} \%$. The Young's modulus of all panels was also increased but began to fall slowly after $0.5 \mathrm{wt} \%$. To investigate this further, Manigandan et al. (2017) manufactured samples of a Kevlar 149 composite, with $2,5,10$, and $20 \mathrm{wt} \%$ of graphene based on the resin weight. They found out that ultimate strength rose as the graphene content increased up to $5 \mathrm{wt} \%$ where a peak increase in ultimate strength of $29 \%$ is evident. However, the 10 and $20 \mathrm{wt} . \%$ samples saw a decrease, with both having a lower UTS than the Kevlar with no graphene added, suggesting there is a limit where the graphene will begin to degrade the performance, rather than improve it.

The successful addition of nanofiller materials has shown to improve mechanical properties. Work has been performed which showed a $146 \%$ improvement in impact strength when incorporating $10 \mathrm{phr}$ halloysite in to Araldite 506 bisphenolA based epoxy resin and 4-4' diaminodiphenylmethane (MDA) hardener (Vahedi et al., 2015). Morphology study showed that the presence of halloysite hindered crack propagation through the brittle matrix thereby toughening the composite. The disparity between matrix and fiber intermolecular properties was reduced by modifying an epoxy resin with silane filler (Yang et al., 2013). In this work 0.5\% w/w N-(2-aminoethyl)3-aminopropyltrimethoxysilane (YDH792) was added to a bisphenol-A based RIMR-135 epoxy resin and RIMU polyamine hardener solution which was infused with T700 $12 \mathrm{~K}$ carbon fibers under a vacuum. The flexural strength, flexural modulus and ILSS increased by 44,35 , and $42 \%$, respectively. It was reported that the lower viscosity of epoxy and YDH792 improved wettability which was evident in results showing the reduction in contact angle from 85 to $80^{\circ}$. Additionally, the covalent bonds formed between YDH792 and hydroxyl groups on the carbon fiber surface and between YDH792 with amine groups/RIMR-135 epoxy groups improve the interfacial and matrix mechanical properties. This two-way covalent interaction between nanofillers-carbon fibers and nanofillersmatrix provides unique way to integrating all components of CFRC which is responsible for improved mechanical properties.

Shin et al. (2012) reported on the mechanical and thermal properties of carbon fiber-reinforced composites with GO, rGO, and carbon nanotubes. The tensile evaluation of the GO/epoxy CFRC samples with GO showed increase in the tensile modulus between 0 and 0.3 wt.\% of GO and plateaued out between 0.3 and 0.4 wt.\% and increased until 0.5 wt.\% GO and achieved a $49 \%$ increase in energy absorption, when compared to the neat sample. GO and rGO also exhibited superior tensile properties compared to carbon nanotubes and was therefore selected as the most appropriate filler when attempting to increase tensile properties.

Watson et al. (2017) also studied the mechanical properties of GO/epoxy CFRC samples using GO as a filler. They noted an, insignificantly increase in the flexural modulus of the specimens as the concentration of GO increased. Figure $\mathbf{6}$ shows fracture surface morphology indicating adhesion failure on GO reinforced samples.

Despite the flexural modulus showing a minor increase, the results for flexural strength of the specimens failed to form a linear relationship and showed an overall decrease from the lowest concentration to the highest. The results obtained by Watson et al. (2017) had divergence from a study by Pathak et al. (2016) who reported that the yield flexural strength and the flexural modulus steadily increasing between the neat samples until their peak at $0.3 \mathrm{wt} . \%$ GO. The results then decreased from 0.3 through $0.6 \mathrm{wt} . \%$, but with each concentration still having higher flexural strength and modulus than the neat samples. They concluded that the higher concentration of GO suffered from poor dispersion 


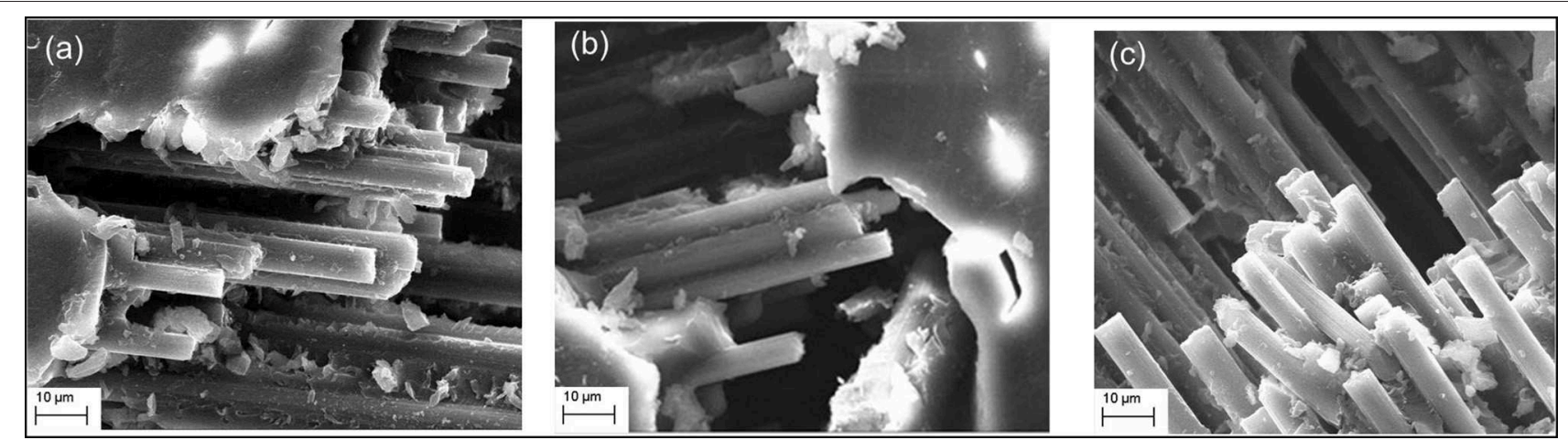

FIGURE 7 | SEM images of fracture surface (a) pure epoxy/carbon fiber composite, (b) 0.3wt.\% GO/epoxy/carbon fiber composite, and (c) 0.5 wt.\% GO/epoxy/carbon fiber composite.

due to the GO aggregating and agglomerating within the dispersal agent.

There are currently limited publications in the open literature on shear properties and thermo-mechanical properties of $\mathrm{GO} /$ epoxy fiber-reinforced composites. Of particular interest is the effect of temperature changes on mechanical properties that is relevant and specific to applications such as the aerospace, racing cars, marine and automotive industry where temperature changes can vary significantly in lightweight applications (Pielichowski and Njuguna, 2005; Njuguna, 2016). It is wellknown that temperature can have a significant impact on the shear and flexural strength of composite materials and that the addition of nanofiller may have some effect on how temperature influences strength.

A most recent study by Jenkins et al. (2019) focused on the evaluation of epoxy/carbon fiber-reinforced composite containing varying quantities of $\mathrm{rGO}$ and examine the shear and flexural properties of these samples at varying temperatures form -10 to $40^{\circ} \mathrm{C}$. They employed the resin infusion technique to manufacture the hybrid composites as demonstrated on Figure 7.

It was found that the composites' flexural strength and flexural modulus increased with rGO wt.\% content up to 62 and $44 \%$, respectively. The results show similar performance to a similar investigation conducted on the addition of GO to a composite. The shear testing results showed improvement on the shear strength and modulus at maximum of 6 and 40\%, respectively. The rGO improvements advantage was lost for flexural strength, shear strength and modulus at elevated temperatures while flexural modulus withheld at $40 \%$ improvements over virgin epoxy/carbon fiber-reinforced composite. An interesting observation is that all samples with rGO exhibit reduced damage characteristics superior to the neat samples under flexural and shear loading conditions. The study indicated that the addition of rGO significantly alter the flexural and shear properties, failure modes, damage characteristics and they are overall sensitive to elevated temperature conditions. The utilization of rGO on composites components depends on full understanding of the mechanical properties and their functional performance. Konios et al. (2014) studied the dispersion of GO and rGO in various media, Chen et al. studied electromagnetic properties
(Chen et al., 2016), cryogenic performance (Wu et al., 2017; He et al., 2018), and other researchers on rGO investigated fatigue performance (Bortz et al., 2011).

\section{Interlaminar Shear Strength (ILSS)}

Before discussing the potential benefits of reinforcing the CFRC interface with graphene it is important to contextualize the wider field with a brief overview of industry tried and tested methods and other areas of research that focus on enhancing the interface. In industry sizing is applied to the carbon fiber surface to (1) primarily protect the fragile fiber filaments from breaking during spinning and fabric processing and (2) improve the properties of the interface between fiber and polymer (Hughes, 1991). Sizing is generally proprietary, and information is often not readily available but in principle sizing consists of a mixture of chemicals that create surface barrier on the carbon fiber surface (e.g., film forming agent) and activate the molecular interaction (e.g., coupling agent). The specific type of sizing depends on the type of carbon fiber, polymer and application therefore significant research is focused on sizing design.

Carbon fiber sizing was removed and changes in IFSS on T300B and T700SC carbon fibers were studied (Dai et al., 2011). The fiber was supplied with proprietary sizing material of unknown composition. After removal with acetone microbond testing was performed with epoxy and identified that IFSS increased by 38 and $9 \%$ for T300B and T700SC fibers, respectively after de-sizing. The work also characterized the surface total energy and showed that an increase from 40 to $45 \mathrm{~mJ} / \mathrm{m}^{2}$ for T300B and decreased from 49 to $45 \mathrm{~mJ} / \mathrm{m}^{2}$ for T700SC. The total surface energy is made-up of the polar component and dispersive component. FTIR analysis of the sizing material showed it to be epoxy based. After desizing was performed surface energy polar components for both fibers decreased due to the removal of polar groups (epoxy, hydroxyl and ether). However, this was accompanied by a rise in the dispersive component due to the increased amount of exposed reactive fiber edges and an increase in surface roughness. The acidic parameter was also observed to decrease by $14-20 \%$ after sizing was removed which favors bonding between acidic resin hardener and epoxy. In this work 
the dispersive component dominated and as a result sizing was shown to be detrimental to IFSS; regardless, information was not given about sizing and epoxy compatibility. Separate work (Montes-Morán et al., 2002) studied adsorption properties four types of carbon fiber; un-treated and un-sized; oxidized; thin sizing coating; and thick sizing coating. The adsorption characteristics of $n$-alkanes on the carbon fibers were studied and showed that the adsorption free energy $(-\Delta G)$ and surface free energy dispersive component reduced in samples that were sized which indicates relatively poor adhesive forces which agrees with results (Dai et al., 2011). Whereas other work synthesized and tested a novel sizing material composed of $10 \% \mathrm{w} / \mathrm{w}$ E51 bisphenol-A based epoxy resin in acetone (Ren et al., 2006). The sizing was applied to high modulus M40J-3K-40B carbon fiber with CFRC fabricated with 2,2' -bis(4cyanatophenyl) isopropylidine (BADCy) resin. Mechanical test results showed an improvement of 4 and 13\% in flexural strength and ILSS, respectively.

Therefore, sizing is a compromise and there is typically a trade-off between functioning as a protective layer during fiber manufacturing and enhancing the fiber/matrice bond in the application. Additional consideration should be given to the difference between low and high modulus carbon fiber surface structures. High modulus PAN based carbon fibers undergo high temperature graphitization which creates an aligned graphene surface structure with fewer surface defects compared to low modulus carbon fiber. For this reason, an oxidative or etching pre-treatment is normally required (Pittman et al., 1997; Jang and Yang, 2000; Köster and Schwartz, 2000; Ma et al., 2011; Tiwari et al., 2012; Borooj et al., 2016).

A common dry treatment technique is to etch the fiber surface via plasma treatment. Research has shown that when optimized plasma treatment of un-sized carbon fibers ( $3 \mathrm{~K}$ tow) in an atmosphere of oxygen had carried out before preparing the composite samples with bisphenol-A based Epon epoxy resin, the inter-laminar shear strength (ILSS) was increased by $31 \%$ from 65 to $86 \mathrm{MPa}$ (Borooj et al., 2016). The presence of hydroxyl and carboxyl group on surface of the carbon fibers confirmed that the oxygen functionalities on the surface improved the molecular interaction between fibers and epoxy. Furthermore, the rougher surface morphology of fibers after plasma treatment observed by microscopy provided large surface area and also promoted the better bonding between fibers and matrix through mechanical interlocking. The modification increased the wettability of the carbon fiber surface by increasing the surface free energy and the plasma treatment showed a range of improvement in ILSS. Similar work (Köster and Schwartz, 2000; Ma et al., 2011) has shown improvements in ILSS of $18 \%$ and interfacial shear stress (IFSS) of 50\%, respectively.

Other dry treatment processes have reported successful functionalisation of the fiber surface with oxygen groups; Liu et al. (2015) showed that gamma-irradiating T700 fibers in an argon atmosphere reduced the subsequent contact angle of the fiber with water from 107 to $80^{\circ}$ and increased the surface energy from 13.5 to $25.9 \mathrm{~mJ} / \mathrm{m}^{2}$. The improvement in wettability improve the interfacial properties between carbon fiber and epoxy; the improvement in adhesion was also demonstrated elsewhere (Tiwari et al., 2011).

Wet chemical oxidation of fiber is another viable method to functionalise carbon fiber and improve the interface properties (Pittman et al., 1997; Jang and Yang, 2000; Tiwari et al., 2012). However, both dry and wet treatment techniques involve using high energy radiation or strong acid and oxidizing conditions which can result in excessive damage to the carbon fiber structure. Therefore, potential benefits realized in flexural properties can compromise the in-plane tensile properties.

Polymer modification also improves its compatibility with carbon fiber and hence, enhances mechanical properties through improved compatibility with the carbon fiber reinforcement. This was demonstrated by performing a multi-step process to functionalise $\mathrm{SiO}_{2}$ powders with diglycidyl ether of bisphenol-A (DGEBA) (Zhou et al., 2015). The functionalised $\mathrm{SiO}_{2}(12 \%$ w/w) was polymerized with BPADE epoxy resin and methyl hexahydrophthalic anhydride hardener and cured. Resulting composite demonstrated a $40 \%$ improvement in flexural strength which was attributed to an increase in entropy caused by the favorable molecular interactions between the epoxy functional groups on the functionalised $\mathrm{SiO}_{2}$ and the BPADE resin/hardener mix. The additional epoxy concentration increased the cross-link density of covalent bonds during polymerization causing improvement in the composite matrix mechanical properties.

\section{Impact Performance}

Low and high velocity-impact testing has a particular interest, compared to metallic materials, fiber-reinforced composites (FRC) have orthotropic mechanical properties which lead to very complex failure such as micro-buckling and delamination. Vahedi et al. (2015) reported 146\% improvement in impact strength after incorporating 10 phr halloysite in to Araldite 506 bisphenol-A based epoxy resin and 4-4'diaminodiphenylmethane (MDA) hardener (Vahedi et al., 2015). Zanjani et al. (2018) and Zanjani et al. (2016) employ introduced thermally exfoliated GO (TEGO) to the fiber surface and matrix and demonstrated a good improvement in overall properties and improved impact strength by $30 \%$.

Another interesting study compared the nanoclay Cloisite $30 \mathrm{~B}$, with a non-functionalised graphene filler (Rahman et al., 2014). Their research suggestsed that the addition of nonfunctionalised graphene did not increase the impact resistance of the laminate. This is in contrast to other fillers such as nanosilica that were reported to improve the compression-afterimpact strength of a carbon fiber-reinforced nanocomposite filler using nanosilica and rubber particle enhancement (Nikfar and Njuguna, 2014). The study found out that using silica nanoparticles in the materials resin improved the impact resistance and the residual compressive strength of the material when compared to the same material without the addition of the nanosilica. A 50\% smaller delamination area for the test specimens was discovered, which is a significant improvement 
on their predecessors. A marginal improvement of $11 \%$ in the Young's modulus of the carbon fiber was also reported, as well as a $4 \%$ increase in the U.T.S. (ultimate tensile strength). Another nanomaterial being researched for the improved properties of composite materials is carbon nanotubes. Taraghi et al. (2014) have researched the low-velocity response of woven epoxyKevlar laminated composites which have been reinforced by multi-walled carbon nanotubes (MWCNTs) at ambient and low temperatures of $-40^{\circ} \mathrm{C}$. The research states that the addition of MWCNTs resulted in a decreased damage size and a diminished delamination area, due to the bridging of nanotubes between the matrix and Kevlar fibers. It was found out that the MWCNTs increased the absorbable energy, bending stiffness and penetration limit at both ambient and low temperatures compared to the baseline composite.

\section{FUTURE PERSPECTIVE/OUTLOOK}

The CFRP industry is well-established with many applications across a range of industries which have a need for ultra-strong and low-weight materials. With this existing demand there is a latent need for continued improvement as companies compete to deliver more technologically advanced solutions. In addition to this, future demand for CFRP is likely to evolve at an everincreasing rate. The Species has a growing desire to explore the solar system and make space accessible to the public and the economics of this industry rely heavily on ultra-strong and low-weight materials. In addition, the public are becoming more aware of the impact that the species has on the planet. Considering our finite resources of materials and the huge energy costs involved in producing metals then there will be an ever-increasing drive to utilize novel and more environmentally friendly materials in the future. Research and development within the materials science field is crucial to meeting the future demands and graphene-based materials have a role to play (Zhu et al., 2017).

The research work reported here and elsewhere has proven that nanofiller derived from graphene can improve CFRP performance. Surface modification of CFRP with graphene-based molecules has demonstrated generous improvements in interface mechanical properties and these techniques can be developed further. However, in order to realize the next generation of CFRP both surface and matrix modification techniques need to be combined to reinforce not only the interface but also the matrix. The greatest challenge faced is to identify suitable techniques which can achieve an efficient dispersion of graphenebased molecules in the polymer phase. Graphene oxide is an extremely flexible molecule and there is huge potential to develop the techniques described in this report to better improve the intermolecular attractions between graphene based nanofiller and matrix. Achieving an economic and uniform dispersion is critical for the establishment of a graphene CFRP industry. There is significant potential and opportunity for the chemistry, polymer and materials science fields to overlap, collaborate and develop ever more novel techniques to incorporate graphenebased molecules in to CFRP.
This paper has focused primarily on mechanical property improvements through the inclusion of graphene-based molecules in CFRP; for which there is clear demand. However the wider graphene industry has many more other applications; for example as a material to manufacture sensors (Nag et al., 2018; Xiang et al., 2018a) and as touched on briefly in this paper as a means to improve materials electronic properties (Xiang et al., 2018b). Taking a holistic overview of the graphene industry demonstrates that there is great value in continued research and development in order to meet a very real market demand.

The design rules are suggested as hold-points for materials scientists to plan future work.

i. It is critical to appreciate that graphene oxide is not a "one size fits all" molecule. GO is a hugely variable molecule in terms of both chemical composition and physical nature (i.e., size). The synthesis technique directly influences the resultant oxygen content, surface structure and functional groups that are present in produced GO. This in-turn influences dispersion and interactions with fiber and matrix; further functionalisation options and propensity to reinforce CFRP (e.g., molecular size). Therefore, synthesis technique and feed-stock must be selected based on the final CFRP application in order to achieve best results.

ii. The Hummers and modified methods offer the most flexibility and up-scalability when compared to other contemporary methods. Routes such as CVD or planetary ball milling do not produce the yield or chemical flexibility that oxidized graphite via Hummers method offers. In the engineering context a trade-off between up-scalability and synthesis complexity, including work-up is envisaged. Additional work is required in this area to better understand how sensitive application is to minor variances in GO type. Determining that GO produced by a facile reaction with simple work-up has application within CFRP would lead on to potential industrial applications.

iii. Covalent modification of the carbon fiber surface has been proven to improve interfacial mechanical properties. This technique can redefine the weak-point in the composite from the interface, where de-bonding is the typical failure mode, and transfer the failure point in to the matrix. This approach naturally leads to research opportunities within matrix modification in order to universally improve CFRP constituents' mechanical properties. EPD, dipping and spraying are viable carbon fiber surface modifications providing that application does not necessitate significantly improved interfacial properties.

iv. Matrix modification by simply mixing graphene based nanofiller has demonstrated variable results and the literature shows often conflicting evidence of improvement. Analysis of failure surfaces continually demonstrate that agglomeration of nanofiller is counterproductive and acts as a stress concentrator. Existing dispersion techniques such as solvent dispersion are not ideal because they do not address subsequent issues of nanofiller agglomeration (after solvent extraction) and solvent carry over is prone to 
negatively affecting CFRP properties. The cure kinetics need to be better understood for the modified epoxy matric and their composites.

v. Graphene based nanofiller tends to agglomerate due to the differences in chemical properties of filler compared to epoxy. Therefore, there is presently no mechanical or processing method which can solve this issue. Improving the dispersibility of graphene based nanofiller in epoxy can only be done by chemical modification of the nanofiller or the polymer. GO has a diverse content of functional groups and offers the most flexibility for continued research in to surface functionalisation to alter polarity to improve affinity with and dispersion in epoxy.

vi. From a mechanical properties perspective reduced graphene oxide remains challenging. Molecules of rGO are less flexible and more prone to agglomerate due to the reduced surface functionality and increased content of $\mathrm{sp}^{2}$ carbon. For this reason, mechanical properties of $\mathrm{rGO} /$ epoxy composites tend to be lower than GO/epoxy composites. It is notable, however, that the reduction of GO partly restores the structure and properties of graphene is a key topic in the research at present. Different reduction processes result in different properties of reduced GO (rGO), which in turn affect the final performance of materials or devices composed of rGO. Also, nanofilling of rGO to epoxy/carbon fiber nanocomposites is a relatively new approach with a high interest to fiber reinforced composite manufacturing of components due to its potential in properties and performance improvements. Publications on rGO/epoxy-fiber reinforced composites are scarse in the open literature.

vii. Low to mid modulus carbon fibers offer the most potential for constructing composites that potentially have comparable constituent mechanical properties (i.e., fiber $\approx$ interface $\approx$ matrix). The defects present on low-modulus fibers offer additional sites to functionalise the fiber surface without having to perform aggressive oxidation and causing structural damage. High modulus fibers are aligned with minimal surface defects and require aggressive oxidation or plasma treatment to add surface functionalities however this damage the outer layer of the fiber. There is also an obvious cost benefit from using low-modulus fibers.

\section{REFERENCES}

Abdolhosseinzadeh, S., Asgharzadeh, H., and Kim, H. S. (2015). Fast and fully-scalable synthesis of reduced graphene oxide. Sci. Rep. 5:10160. doi: 10.1038/srep10160

Al-Sherbini, A., Bakr, M., Ghoneim, I., and Saad, M. (2017). Exfoliation of graphene sheets via high energy wet milling of graphite in 2-ethylhexanol and kerosene. J. Adv. Res. 8, 209-215. doi: 10.1016/j.jare.2017.01.004

Antisari, M. V., Montone, A., Jovic, N., Piscopiello, E., Alvani, C., and Pilloni, L. (2006). Low energy pure shear milling: a method for the preparation of graphite nano-sheets. Scripta Mater. 55, 1047-1050. doi: 10.1016/j.scriptamat.2006.08.002

\section{CONCLUSIONS}

This work covers recent advances in carbon fiber, epoxy and graphene composite nanomaterials. We have explored the graphene derivatives, synthesis techniques and identifying popular methods utilized in CFRC. The primary focus on tailoring for the mechanical properties through the carbon fiber surface modification, epoxy polymer modification (covalent and non-covalent), composite processing techniques and nanofiller dispersion in epoxy. It is shown that GO dispersions challenges are the bottleneck on polymer modification in that it improves its compatibility with carbon fiber and hence, enhances mechanical properties through improved compatibility with the carbon fiber reinforcement.

The covalent interaction between nanofillers-carbon fibers and nanofillers-matrix provides unique way to integrating all components of CFRC which is responsible for improved mechanical properties. It is also noted that carbon fiber sizing is a surface treatment which is often proprietary and commercially sensitive should also be incorporated in to control experiments in addition to analysis of un-sized fibers and epoxy. Significant studies have been conducted with success on to improve wettability and better intermolecular interactions at the interface improved mechanical properties. This work provides some excellent examples demonstrating how mechanical performance can be improved depending on modification technique, however it also validates that for engineering applications will require a compromise between properties and complexity (i.e., unit operations and processability) may be required.

In summary, the review study showed that there is a general hierarchy to composite constituent strengths whereby without any modification the strength from strongest to weakest is first fiber, second matrix and third the interface. There is great potential for the materials scientist to take a holistic approach to improving overall composite properties by utilizing several modification techniques to improve composite properties.

\section{AUTHOR CONTRIBUTIONS}

JK: prepared manuscript draft. KP: drafting, supervision, and advisory. JN: drafting, structure, and study design.

Atif, R., Shyha, I., and Inam, F. (2016). Mechanical, thermal, and electrical properties of graphene-epoxy nanocomposites-A review. Polymers 8:281. doi: $10.3390 /$ polym 8080281

Baral, N., Guezenoc, H., Davies, P., and Baley, C. (2008). High modulus carbon fibre composites: correlation between transverse tensile and mode I interlaminar fracture properties. Mater. Lett. 62, 1096-1099. doi: 10.1016/j.matlet.2007.07.071

Bari, P., Khan, S., Njuguna, J., and Mishra, S. (2017). Elaboration of properties of graphene oxide reinforced epoxy nanocomposites. Int. J. Plastics Technol. 21, 194-208. doi: 10.1007/s12588-017-9180-9

Bascom, W. D., and Drzal, L. (1987). The Surface Properties of Carbon Fibers and Their Adhesion to Organic Polymers. 
Borooj, M. B., Shoushtari, A. M., Haji, A., and Sabet, E. N. (2016). Optimization of plasma treatment variables for the improvement of carbon fibres/epoxy composite performance by response surface methodology. Compos. Sci. Technol. 128, 215-221. doi: 10.1016/j.compscitech.2016.03.020

Bortz, D. R., Heras, E. G., and Martin-Gullon, I. (2011). Impressive fatigue life and fracture toughness improvements in graphene oxide/epoxy composites. Macromolecules 45, 238-245. doi: 10.1021/ma201563k

Botas, C., Álvarez, P., Blanco, P., Granda, M., Blanco, C., Santamaría, R., et al. (2013). Graphene materials with different structures prepared from the same graphite by the Hummers and Brodie methods. Carbon 65, 156-164. doi: 10.1016/j.carbon.2013.08.009

Bradley, R., Ling, X., and Sutherland, I. (1993). An investigation of carbon fibre surface chemistry and reactivity based on XPS and surface free energy. Carbon 31, 1115-1120. doi: 10.1016/0008-6223(93)90064-H

Ceriotti, G., Romanchuk, A. Y., Slesarev, A. S., and Kalmykov, S. N. (2015). Rapid method for the purification of graphene oxide. RSC Adv. 5, 50365-50371. doi: 10.1039/C5RA07604H

Chen, J., Li, Y., Huang, L., Li, C., and Shi, G. (2015). High-yield preparation of graphene oxide from small graphite flakes via an improved Hummers method with a simple purification process. Carbon 81, 826-834. doi: 10.1016/j.carbon.2014.10.033

Chen, J., Wu, J., Ge, H., Zhao, D., Liu, C., and Hong, X. (2016). Reduced graphene oxide deposited carbon fiber reinforced polymer composites for electromagnetic interference shielding. Compos. Part A Appl. Sci. Manufact. 82, 141-150. doi: 10.1016/j.compositesa.2015.12.008

Chen, L., Jin, H., Xu, Z., Shan, M., Tian, X., Yang, C., et al. (2014). A design of gradient interphase reinforced by silanized graphene oxide and its effect on carbon fiber/epoxy interface. Mater. Chem. Phys. 145, 186-196. doi: 10.1016/j.matchemphys.2014.02.001

Dai, Z., Shi, F., Zhang, B., Li, M., and Zhang, Z. (2011). Effect of sizing on carbon fiber surface properties and fibers/epoxy interfacial adhesion. Appl. Surface Sci. 257, 6980-6985. doi: 10.1016/j.apsusc.2011.03.047

Das, S., Warren, J., West, D., and Schexnayder, S. M. (2016). Global Carbon Fiber Composites Supply Chain Competitiveness Analysis.

Deng, C., Jiang, J., Liu, F., Fang, L., Wang, J., Li, D., et al. (2015). Effects of electrophoretically deposited graphene oxide coatings on interfacial properties of carbon fiber composite. J. Mater. Sci. 50, 5886-5892. doi: 10.1007/s10853-015-9138-2

Deng, C., Jiang, J., Liu, F., Fang, L., Wang, J., Li, D., et al. (2016). Influence of surface properties of graphene oxide/carbon fiber hybrid fiber by oxidative treatments combined with electrophoretic deposition. Surface Interface Anal. 48, 212-217. doi: 10.1002/sia.5944

Dimiev, A. M., and Tour, J. M. (2014). Mechanism of graphene oxide formation. ACS Nano 8, 3060-3068. doi: 10.1021/nn500606a

Dreyer, D. R., Park, S., Bielawski, C. W., and Ruoff, R. S. (2010). The chemistry of graphene oxide. Chem. Soc. Rev. 39, 228-240. doi: 10.1039/B917103G

Drzal, L., Sugiura, N., and Hook, D. (1996). The role of chemical bonding and surface topography in adhesion between carbon fibers and epoxy matrices. Compos. Interfaces 4, 337-354. doi: 10.1163/156855497X00073

Du, X., Zhou, H., Sun, W., Liu, H., Zhou, G., Zhou, H., et al. (2017). Graphene/epoxy interleaves for delamination toughening and monitoring of crack damage in carbon fibre/epoxy composite laminates. Compos. Sci. Technol. 140, 123-133. doi: 10.1016/j.compscitech.2016.12.028

European Stainless Steel Development Association (2007). Stainless Steel: Tables of Technical Properties. Materials and Application Series.

Feicht, P., Siegel, R., Thurn, H., Neubauer, J. W., Seuss, M., Szabó, T., et al. (2017). Systematic evaluation of different types of graphene oxide in respect to variations in their in-plane modulus. Carbon 114, 700-705. doi: 10.1016/j.carbon.2016.12.065

Feng, L., Li, K., Xue, B., Fu, Q., and Zhang, L. (2017). Optimizing matrix and fiber/matrix interface to achieve combination of strength, ductility and toughness in carbon nanotube-reinforced carbon/carbon composites. Mater. Des. 113, 9-16. doi: 10.1016/j.matdes.2016.10.006

Feraboli, P., and Masini, A. (2004). Development of carbon/epoxy structural components for a high performance vehicle. Compos. Part B Eng. 35, 323-330. doi: 10.1016/j.compositesb.2003.11.010

Garcia, M., Davis, B., and Miller, J. (2017). Hypervelocity impact testing of a pressurized composite overwrapped pressure vessel and comparison to numerical analysis. Procedia Eng. 204, 476-483. doi: 10.1016/j.proeng.2017.09.744

Gojny, F. H., Wichmann, M. H. G., Kopke, U., Fieldler, B., and Schulte, K. (2014). Carbon nanotube-reinforced epoxy-composites: enhanced stiffness and fracture toughness at low nanotube content. Compos. Sci. Technol. 64, 2363-2371. doi: 10.1016/j.compscitech.2004.04.002

Han, X., Zhao, Y., Sun, J., Li, Y., Zhang, J., and Hao, Y. (2017). Effect of graphene oxide addition on the interlaminar shear property of carbon fiber-reinforced epoxy composites. New Carbon Mater. 32, 48-55. doi: 10.1016/S1872-5805(17)60107-0

He, H., Klinowski, J., Forster, M., and Lerf, A. (1998). A new structural model for graphite oxide. Chem. Phys. Lett. 287, 53-56. doi: 10.1016/S0009-2614(98)00144-4

He, Y., Yang, S., Liu, H., Shao, Q., Chen, Q., Lu, C., et al. (2018). Reinforced carbon fiber laminates with oriented carbon nanotube epoxy nanocomposites: magnetic field assisted alignment and cryogenic temperature mechanical properties. J. Colloid Interface Sci. 517, 40-51. doi: 10.1016/j.jcis.2018.01.087

Hernandez, Y., Nicolosi, V., Lotya, M., Blighe, F. M., Sun, Z., De, S., et al. (2008). High-yield production of graphene by liquid-phase exfoliation of graphite. Nat. Nanotechnol. 3:563. doi: 10.1038/nnano.2008.215

Holt, J., Mindlin, H., and Ho, C. (1996). Structural Alloys Hand-Book CINDAS West Lafayette, IN: Purdue University.

Huang, S., Wu, G., Chen, C., Yang, Y., Zhang, S., and Lu, C. (2013). Electrophoretic deposition and thermal annealing of a graphene oxide thin film on carbon fiber surfaces. Carbon 52, 613-616. doi: 10.1016/j.carbon.2012.09.062

Hughes, J. (1991). The carbon fibre/epoxy interface-a review. Compos. Sci. Technol. 41, 13-45. doi: 10.1016/0266-3538(91)90050-Y

Hummers, W. S. Jr., and Offeman, R. E. (1958). Preparation of graphitic oxide. J. Am. Chem. Soc. 80, 1339-1339. doi: 10.1021/ja01539a017

Jang, J., and Yang, H. (2000). The effect of surface treatment on the performance improvement of carbon fiber/polybenzoxazine composites. J. Mater. Sci. 35, 2297-2303. doi: 10.1023/A:1004791313979

Jenkins, P., Siddique, S., Khan, S., Usman, A., Starost, K., MacPherson, A., et al. (2019). Influence of reduced graphene oxide on epoxy/carbon fiber-reinforced hybrid composite: flexural and shear properties under varying temperature conditions. Adv. Eng. Mater. 2019:1800614. doi: 10.1002/adem.201800614

Jiang, J., Yao, X., Xu, C., Su, Y., Zhou, L., and Deng, C. (2017). Influence of electrochemical oxidation of carbon fiber on the mechanical properties of carbon fiber/graphene oxide/epoxy composites. Compos. Part A Appl. Sci. Manufact. 95, 248-256. doi: 10.1016/j.compositesa.2017.02.004

Kamar, N. T., Hossain, M. M., Khomenko, A., Haq, M., Drzal, L. T., and Loos, A. (2015). Interlaminar reinforcement of glass fiber/epoxy composites with graphene nanoplatelets. Compos. Part A Appl. Sci. Manufact. 70, 82-92. doi: 10.1016/j.compositesa.2014.12.010

Kang, J. H., Kim, T., Choi, J., Park, J., Kim, Y. S., Chang, M. S., et al. (2016). Hidden second oxidation step of Hummers method. Chem. Mater. 28, 756-764. doi: 10.1021/acs.chemmater.5b03700

Knieke, C., Berger, A., Voigt, M., Taylor, R. N. K., Röhrl, J., and Peukert, W. (2010). Scalable production of graphene sheets by mechanical delamination. Carbon 48, 3196-3204. doi: 10.1016/j.carbon.2010.05.003

Konios, D., Stylianakis, M. M., Stratakis, E., and Kymakis, E. (2014). Dispersion behaviour of graphene oxide and reduced graphene oxide. J. Colloid Interface Sci. 430, 108-112. doi: 10.1016/j.jcis.2014.05.033

Köster, K., and Schwartz, P. (2000). Influence of acetylene plasma treatment on the torsional fatigue of carbon-fiber-reinforced composite strands. Compos. Sci. Technol. 60, 2005-2010. doi: 10.1016/S0266-3538(00)00097-X

Koutroumanis, N., Manikas, A. C., Pappas, P. N., Petropoulos, F., Sygellou, L., Tasis, D., et al. (2018). A novel mild method for surface treatment of carbon fibres in epoxy-matrix composites. Compos. Sci. Technol. 157, 178-184. doi: 10.1016/j.compscitech.2018.01.048

Kukdo (2001). Kukdo YD-128 Product Datasheet. Available online at: https://www. kukdo.com/file/goods/YD-128_TDS_.pdf (accessed 18, 2019).

Kwon, Y. J., Kim, Y., Jeon, H., Cho, S., Lee, W., and Lee, J. U. (2017) Graphene/carbon nanotube hybrid as a multi-functional interfacial reinforcement for carbon fiber-reinforced composites. Compos. Part B Eng. 122, 23-30. doi: 10.1016/j.compositesb.2017.04.005

Lavin-Lopez, M. D. P., Romero, A., Garrido, J., Sanchez-Silva, L., and Valverde, J. L. (2016). Influence of different improved Hummers method modifications 
on the characteristics of graphite oxide in order to make a more easily scalable method. Ind. Eng. Chem. Res. 55, 12836-12847. doi: 10.1021/acs.iecr.6b03533

Lazonick, W., and Prencipe, A. (2005). Dynamic capabilities and sustained innovation: strategic control and financial commitment at Rolls-Royce plc. Ind. Corporate Change 14, 501-542. doi: 10.1093/icc/dth061

Lee, C., Wei, X., Kysar, J. W., and Hone, J. (2008). Measurement of the elastic properties and intrinsic strength of monolayer graphene. Science 321, 385-388. doi: $10.1126 /$ science. 1157996

Lee, D. C., and Jang, L. W. (1998). Characterization of epoxy-clay hybrid composite prepared by emulsion polymerization. J. Appl. Polymer Sci. 68, 1997-2005.

Lee, W., Lee, J. U., Cha, H., and Byun, J. (2013). Partially reduced graphene oxide as a multi-functional sizing agent for carbon fiber composites by electrophoretic deposition. RSC Adv. 3, 25609-25613. doi: 10.1039/c3ra44155e

Li, M., Yuan, C., Wang, S. K., Gu, Y. Z., Potter, K., and Zhang, Z. G. (2013). Evolution of the wettability between carbon fiber and epoxy as a function of temperature and resin curing. J. Appl. Polymer Sci. 128, 4095-4101. doi: 10.1002/app.38634

Li, P., Zheng, Y., Li, M., Shi, T., Li, D., and Zhang, A. (2016a). Enhanced toughness and glass transition temperature of epoxy nanocomposites filled with solventfree liquid-like nanocrystal-functionalized graphene oxide. Mater. Des. 89, 653-659. doi: 10.1016/j.matdes.2015.09.155

Li, Y., Zhao, Y., Sun, J., Hao, Y., Zhang, J., and Han, X. (2016b). Mechanical and electromagnetic interference shielding properties of carbon fiber/graphene nanosheets/epoxy composite. Polymer Compos. 37, 2494-2502. doi: $10.1002 /$ pc.23436

Lian, M., Fan, J., Shi, Z., Li, H., and Yin, J. (2014). Kevlar ${ }^{\circledR}$-functionalized graphene nanoribbon for polymer reinforcement. Polymer 55, 2578-2587. doi: 10.1016/j.polymer.2014.03.059

Liu, L., Wu, F., Yao, H., Shi, J., Chen, L., Xu, Z., et al. (2015). Investigation of surface properties of pristine and $\gamma$-irradiated PAN-based carbon fibers: effects of fiber instinct structure and radiation medium. Appl. Surface Sci. 337, 241-248. doi: 10.1016/j.apsusc.2015.02.101

Liu, L., Yan, F., Li, M., Zhang, M., Xiao, L., Shang, L., et al. (2018). Improving interfacial properties of hierarchical reinforcement carbon fibers modified by graphene oxide with different bonding types. Compos. Part A Appl. Sci. Manufact. 107, 616-625. doi: 10.1016/j.compositesa.2018.02.009

Lu, L., Xia, L., Zengheng, H., Xingyue, S., Yi, Z., and Pan, L. (2018). Investigation on cure kinetics of epoxy resin containing carbon nanotubes modified with hyperbranched polyester. RSC Adv. 8, 29830-29839. doi: 10.1039/C8RA04525A

Luo, Y., Cheng, X., Zhang, X., and Lei, C. (2017). Fabrication of a threedimensional reinforcement via grafting epoxy functionalized graphene oxide onto carbon fibers. Mater. Lett. 209, 463-466. doi: 10.1016/j.matlet.2017.08.049

Lv, P., Feng, Y., Zhang, P., Chen, H., Zhao, N., and Feng, W. (2011). Increasing the interfacial strength in carbon fiber/epoxy composites by controlling the orientation and length of carbon nanotubes grown on the fibers. Carbon 49, 4665-4673. doi: 10.1016/j.carbon.2011.06.064

Ma, K., Wang, B., Chen, P., and Zhou, X. (2011). Plasma treatment of carbon fibers: non-equilibrium dynamic adsorption and its effect on the mechanical properties of RTM fabricated composites. Appl. Surface Sci. 257, 3824-3830. doi: 10.1016/j.apsusc.2010.12.074

Mahmood, H., Tripathi, M., Pugno, N., and Pegoretti, A. (2016). Enhancement of interfacial adhesion in glass fiber/epoxy composites by electrophoretic deposition of graphene oxide on glass fibers. Compos. Sci. Technol. 126, 149-157. doi: 10.1016/j.compscitech.2016.02.016

Manigandan, S., Gunasekar, P., Nithya, S., Revanth, G. D., and Anudeep, A. (2017). "Experimental analysis of graphene nanocomposite on Kevlar. Experimental analysis of graphene nanocomposite on Kevlar," in IOP Conference Series: Materials Science and Engineering (Secunderabad: IOP Publishing).

Marcano, D. C., Kosynkin, D. V., Berlin, J. M., Sinitskii, A., Sun, Z., Slesarev, A., et al. (2010). Improved synthesis of graphene oxide. ACS Nano 4, 4806-4814. doi: $10.1021 / \mathrm{nn} 1006368$

Marketsandmarkets.com (2017). CF \& CFRP Market by End-Use Industry (A๙D, Wind Energy, Automotive, Sports, Civil Engineering, Pipe \& Tank, Marine, Medical E\&E), Resin Type (Thermosetting, Thermoplastic), Manufacturing Process, Raw Material and Region-Global Forecast to 2022. Report Code: CH 2794.

Masuelli, M. (2013). Fiber Reinforced Polymers: The Technology Applied for Concrete Repair. London: BoD-Books on Demand.
McConnell, V. (2008). The Making of Carbon Fiber. Available online at: https:// www.compositesworld.com/articles/the-making-of-carbon-fiber (accessed June 18, 2019).

McLaren Technology Group (2019). Case Study: McLaren P1. Available online at: https:/www.mclaren.com/group/case-studies/case-study-mclarenp1/ (accessed June 18, 2019).

Miracle, D. B., and Donaldson, S. L. (2001). ASM Handbook Volume 21: Composites. 10th ed. Ohio, OH: ASM International.

Miyagawa, H., Rich, M. J., and Drzal, L. T. (2004). Amine-cured epoxy/clay nanocomposites. II. the effect of the nanoclay aspect ratio. J. Polymer Sci. Part B Polymer Phys. 42, 4391-4400. doi: 10.1002/polb.20289

Montes-Morán, M. A., Martínez-Alonso, A., and Tascón, J. M. (2002). Effect of sizing on the surface properties of carbon fibres. J. Mater. Chem. 12, 3843-3850. doi: 10.1039/B202902B

Muzyka, R., Kwoka, M., Smedowski, Ł., Díez, N., and Gryglewicz, G. (2017). Oxidation of graphite by different modified Hummers methods. New Carbon Mater. 32, 15-20. doi: 10.1016/S1872-5805(17)60102-1

Nag, A., Mitra, A., and Mukhopadhyay, S. C. (2018). Graphene and its sensor-based applications: a review. Sensors Actuators A Phys. 270, 177-194. doi: 10.1016/j.sna.2017.12.028

Naito, K., Tanaka, Y., Yang, J., and Kagawa, Y. (2009). Flexural properties of pan- and pitch-based carbon fibers. J. Am. Ceramic Soc. 92, 186-192. doi: 10.1111/j.1551-2916.2008.02868.x

Nakamura, O., Ohana, T., Tazawa, M., Yokota, S., Shinoda, W., Nakamura, O., et al. (2009). Study on the PAN carbon-fiberinnovation for modeling a successful R\&D management-An excited-oscillation management model. Synthesiology 2, 159-169. doi: $10.5571 /$ synth.2.159

Nihtianov, S., Tan, Z., and George, B. (2017). New trends in smart sensors for industrial applications-Part I. IEEE Transac. Ind. Electronics 64, 9592-9594. doi: 10.1109/TIE.2017.2758038

Nikfar, B., and Njuguna, J. (2014). “Compression-after-impact (CAI) performance of epoxy/carbon fibre-reinforced nanocomposites using nanosilica and rubber particle enhancement," in IOP Conference Series: Materials Science and Engineering (Madrid: IOP Publishing).

Njuguna, J. (2016). Lightweight Composite Structures in Transport: Design, Manufacturing, Analysis and Performance. Woodhead Publishing.

Njuguna, J., Pielichowski, K., and Alcock, J. (2007). Epoxy-based fibre reinforced nanocomposites. Adv. Eng. Mater. 9, 835-847. doi: 10.1002/adem.200700118

Novoselov, K. S., Geim, A. K., Morozov, S. V., Jiang, D., Zhang, Y., Dubonos, S. V., et al. (2004). Electric field effect in atomically thin carbon films. Science 306, 666-669. doi: 10.1126/science.1102896

Ojdrovic, R., and Pridmore, A. (2017). "Internal repair of buried pipes with CFRP composites. internal repair of buried pipes with CFRP composites," in ASME 2017 Pressure Vessels and Piping Conference (Waikoloa, HI: American Society of Mechanical Engineers). doi: 10.1115/PVP2017-66076

Page, S., Berg, J., and Månson, J. (2001). Characterization of epoxy resin surface energetics. J. Adhes. Sci. Technol. 15, 153-170. doi: 10.1163/156856101743382

Paiva, M., Bernardo, C., and Nardin, M. (2000). Mechanical, surface and interfacial characterisation of pitch and PAN-based carbon fibres. Carbon 38, 1323-1337. doi: 10.1016/S0008-6223(99)00266-3

Paredes, J., Villar-Rodil, S., Martínez-Alonso, A., and Tascon, J. (2008). Graphene oxide dispersions in organic solvents. Langmuir 24, 10560-10564. doi: 10.1021/la801744a

Park, W. K., Yoon, Y., Kim, S., Choi, S. Y., Yoo, S., Do, Y., et al. (2017). Toward green synthesis of graphene oxide using recycled sulfuric acid via couette-taylor flow. ACS Omega 2, 186-192. doi: 10.1021/acsomega.6b00352

Pathak, A. K., Borah, M., Gupta, A., Yokozeki, T., and Dhakate, S. R. (2016). Improved mechanical properties of carbon fiber/graphene oxide-epoxy hybrid composites. Compos. Sci. Technol. 135, 28-38. doi: 10.1016/j.compscitech.2016.09.007

Phiri, J., Gane, P., and Maloney, T. C. (2017). General overview of graphene: production, properties and application in polymer composites. Mater. Sci. Eng. B 215, 9-28. doi: 10.1016/j.mseb.2016.10.004

Pielichowski, K., and Njuguna, J. (2005). Thermal Degradation of Polymeric Materials. Shawbury: iSmithers Rapra Publishing.

Pimenta, S., and Pinho, S. T. (2011). Recycling carbon fibre reinforced polymers for structural applications: technology review and market outlook. Waste Manag. 31, 378-392. doi: 10.1016/j.wasman.2010.09.019 
Pittman, C. Jr., He, G., Wu, B., and Gardner, S. (1997). Chemical modification of carbon fiber surfaces by nitric acid oxidation followed by reaction with tetraethylenepentamine. Carbon 35, 317-331. doi: 10.1016/S0008-6223(97)89608-X

Pop, E., Varshney, V., and Roy, A. K. (2012). Thermal properties of graphene: fundamentals and applications. MRS Bull. 37, 1273-1281. doi: $10.1557 / \mathrm{mrs} .2012 .203$

Qin, W., Vautard, F., Drzal, L. T., and Yu, J. (2015). Mechanical and electrical properties of carbon fiber composites with incorporation of graphene nanoplatelets at the fiber-matrix interphase. Compos. Part B Eng. 69, 335-341. doi: 10.1016/j.compositesb.2014.10.014

Quan, D., Urdániz, J. L., and Ivanković, A. (2018). Enhancing mode-I and mode-II fracture toughness of epoxy and carbon fibre reinforced epoxy composites using multi-walled carbon nanotubes. Mater. Des. 143, 81-92. doi: 10.1016/j.matdes.2018.01.051

Rafiee, M., Nitzsche, F., Laliberte, J., Hind, S., Robitaille, F., and Labrosse, M. (2019). Thermal properties of doubly reinforced fiberglass/epoxy composites with graphene nanoplatelets, graphene oxide and reduced-graphene oxide. Compos. Part B Eng. 164, 1-9. doi: 10.1016/j.compositesb.2018. 11.051

Rahman, S. F. A., Mahmood, M. R., and Hashim, A. M. (2014). Growth of graphene on nickel using a natural carbon source by thermal chemical vapor deposition. Sains Malaysiana 43, 1205-1211.

Rahmani, H., Najafi, S. H. M., Saffarzadeh-Matin, S., and Ashori, A. (2014). Mechanical properties of carbon fiber/epoxy composites: effects of number of plies, fiber contents, and angle-ply layers. Polymer Eng. Sci. 54, 2676-2682. doi: $10.1002 /$ pen. 23820

Reina, A., Jia, X., Ho, J., Nezich, D., Son, H., Bulovic, V., et al. (2009). Layer area, few-layer graphene films on arbitrary substrates by chemical vapor deposition. Nano Lett. 9, 3087-3087. doi: 10.1021/nl901829a

Ren, P., Liang, G., and Zhang, Z. (2006). Influence of epoxy sizing of carbon-fiber on the properties of carbon fiber/cyanate ester composites. Polymer Compos. 27, 591-598. doi: 10.1002/pc.20230

Rezaei, F., Yunus, R., Ibrahim, N., and Mahdi, E. S. (2008). Development of shortcarbon-fiber-reinforced polypropylene composite for car bonnet. PolymerPlastics Technol. Eng. 47, 351-357. doi: 10.1080/03602550801897323

Rodríguez-González, J., Rubio-González, C., Jiménez-Mora, M., Ramos-Galicia, L., and Velasco-Santos, C. (2018). Influence of the hybrid combination of multiwalled carbon nanotubes and graphene oxide on interlaminar mechanical properties of carbon fiber/epoxy laminates. Appl. Compos. Mater. 25, 1115-1131. doi: 10.1007/s10443-017-9656-y

Romero, A., Lavin-Lopez, M., Sanchez-Silva, L., Valverde, J., and Paton-Carrero, A. (2018). Comparative study of different scalable routes to synthesize graphene oxide and reduced graphene oxide. Mater. Chem. Phys. 203, 284-292. doi: 10.1016/j.matchemphys.2017.10.013

Sa, K., Mahakul, P. C., Das, B., Subramanyam, B., Mukherjee, J., Saha, S., et al. (2018). Large scale synthesis of reduced graphene oxide using ferrocene and $\mathrm{HNO}_{3}$. Mater. Lett. 211, 335-338. doi: 10.1016/j.matlet.2017.10.031

Savage, G. (2008). Composite Materials Technology in Formula 1 Racing (Honda Racing F1 Team).

Seo, D. H., Pineda, S., Fang, J., Gozukara, Y., Yick, S., Bendavid, A., et al. (2017). Single-step ambient-air synthesis of graphene from renewable precursors as electrochemical genosensor. Nat. Commun. 8:14217. doi: $10.1038 /$ ncomms 14217

Sharma, M., Gao, S., Mäder, E., Sharma, H., Wei, L. Y., and Bijwe, J. (2014). Carbon fiber surfaces and composite interphases. Compos. Sci. Technol. 102, 35-50. doi: 10.1016/j.compscitech.2014.07.005

Shin, M. K., Lee, B., Kim, S. H., Lee, J. A., Spinks, G. M., Gambhir, S., et al. (2012). Synergistic toughening of composite fibres by self-alignment of reduced graphene oxide and carbon nanotubes. Nat. Commun. 3:650. doi: $10.1038 /$ ncomms1661

Silva, L. C., Silva, G. G., Ajayan, P. M., and Soares, B. G. (2015). Long-term behavior of epoxy/graphene-based composites determined by dynamic mechanical analysis. J. Mater. Sci. 50, 6407-6419. doi: 10.1007/s10853-015-9193-8

SIR Industriale (2019). Catalogue of Epoxy Resins. Available online at: http://www. sirindustriale.com/EN/documents\%20UK/Brochure\%20EPOSIR-EPONAC. pdf (accessed June 18, 2019).
Soutis, C. (2005). Fibre reinforced composites in aircraft construction. Prog. Aerospace Sci. 41, 143-151. doi: 10.1016/j.paerosci.2005.02.004

Su, C., Lu, A., Xu, Y., Chen, F., Khlobystov, A. N., and Li, L. (2011). Highquality thin graphene films from fast electrochemical exfoliation. ACS Nano 5 , 2332-2339. doi: $10.1021 / \mathrm{nn} 200025 \mathrm{p}$

Sui, X., Shi, J., Yao, H., Xu, Z., Chen, L., Li, X., et al. (2017). Interfacial and fatigue-resistant synergetic enhancement of carbon fiber/epoxy hierarchical composites via an electrophoresis deposited carbon nanotube-toughened transition layer. Compos. Part A Appl. Sci. Manufact. 92, 134-144. doi: 10.1016/j.compositesa.2016.11.004

Sun, F., Yu, T., Hu, C., and Li, Y. (2016). Influence of functionalized graphene by grafted phosphorus containing flame retardant on the flammability of carbon fiber/epoxy resin (CF/ER) composite. Compos. Sci. Technol. 136, 76-84. doi: 10.1016/j.compscitech.2016.10.002

Surnova, A., Balkaev, D., Musin, D., Amirov, R., and Dimiev, A. M. (2019). Fully exfoliated graphene oxide accelerates epoxy resin curing, and results in dramatic improvement of the polymer mechanical properties. Compos. Part B Eng. 162, 685-691. doi: 10.1016/j.compositesb.2019. 01.020

Tang, L., Li, X., Ji, R., Teng, K. S., Tai, G., Ye, J., et al. (2012). Bottom-up synthesis of large-scale graphene oxide nanosheets. J. Mater. Chem. 22, 5676-5683. doi: 10.1039/c2jm15944a

Taraghi, I., Fereidoon, A., and Taheri-Behrooz, F. (2014). Low-velocity impact response of woven Kevlar/epoxy laminated composites reinforced with multiwalled carbon nanotubes at ambient and low temperatures. Mater. Design 53 , 152-158. doi: 10.1016/j.matdes.2013.06.051

The Editors of Encyclopaedia Britannica (2018). Joseph Swan. Available online at: https://www.britannica.com/biography/Joseph-Wilson-Swan (accessed June $18,2019)$.

Tiwari, S., Bijwe, J., and Panier, S. (2011). Gamma radiation treatment of carbon fabric to improve the fiber-matrix adhesion and tribo-performance of composites. Wear 271, 2184-2192. doi: 10.1016/j.wear.2010.11.032

Tiwari, S., Bijwe, J., and Panier, S. (2012). Optimization of surface treatment to enhance fiber-matrix interface and performance of composites. Wear 274, 326-334. doi: 10.1016/j.wear.2011.09.014

Toshev, B. (2006). Gibbs' thermodynamics of wetting. Int. J. Mech. Eng. Edu. 34, 256-262. doi: 10.7227/IJMEE.34.3.6

Trimble, S. (2013). Betting big on composites: after decades of research, GE's ceramic matrix composite technology is set to come of age in the GE9X turbofan that will power the Boeing 777X. Flight Int. 184:1.

Vahedi, V., Pasbakhsh, P., and Chai, S. (2015). Toward high performance epoxy/halloysite nanocomposites: new insights based on rheological, curing, and impact properties. Mater. Des. 68, 42-53. doi: 10.1016/j.matdes.2014.12.010

Vautard, F., Grappe, H., Ozcan, S. (2013). Stability of carbon fiber surface functionality at elevated temperatures and its influence on interfacial adhesion. Appl. Surface Sci. 268, 61-72. doi: 10.1016/j.apsusc.2012.11.158

Wan, Y., Tang, L., Gong, L., Yan, D., Li, Y., Wu, L., et al. (2014). Grafting of epoxy chains onto graphene oxide for epoxy composites with improved mechanical and thermal properties. Carbon 69, 467-480. doi: 10.1016/j.carbon.2013.12.050

Wang, C., Li, J., Sun, S., Li, X., Zhao, F., Jiang, B., et al. (2016). Electrophoretic deposition of graphene oxide on continuous carbon fibers for reinforcement of both tensile and interfacial strength. Compos. Sci. Technol. 135, 46-53. doi: 10.1016/j.compscitech.2016.07.009

Wang, C., Li, J., Yu, J., Sun, S., Li, X., Xie, F., et al. (2017a). Grafting of sizecontrolled graphene oxide sheets onto carbon fiber for reinforcement of carbon fiber/epoxy composite interfacial strength. Compos. Part A Appl. Sci. Manufact. 101, 511-520. doi: 10.1016/j.compositesa.2017.07.015

Wang, C., Zhao, M., Li, J., Yu, J., Sun, S., Ge, S., et al. (2017b). Silver nanoparticles/graphene oxide decorated carbon fiber synergistic reinforcement in epoxy-based composites. Polymer 131, 263-271. doi: 10.1016/j.polymer.2017.10.049

Wang, D., Wang, Z., Smith, S. T., and Yu, T. (2017c). Seismic performance of CFRP-confined circular high-strength concrete columns with high axial compression ratio. Construct. Build. Mater. 134, 91-103. doi: 10.1016/j.conbuildmat.2016.12.108

Wang, P., Yang, J., Liu, W., Tang, X., Zhao, K., Lu, X., et al. (2017d). Tunable crack propagation behavior in carbon fiber reinforced plastic laminates with 
polydopamine and graphene oxide treated fibers. Mater. Des. 113, 68-75. doi: 10.1016/j.matdes.2016.10.013

Wang, X., You, H., Liu, F., Li, M., Wan, L., Li, S., et al. (2009). Large-scale synthesis of few-layered graphene using CVD. Chem. Vapor Depos. 15, 53-56. doi: 10.1002/cvde.200806737

Watson, G., Starost, K., Bari, P., Faisal, N., Mishra, S., and Njuguna, J. (2017). "Tensile and flexural properties of hybrid graphene oxide/epoxy carbon fibre reinforced composites. Tensile and flexural properties of hybrid graphene oxide/epoxy carbon fibre reinforced composites," in IOP Conference Series: Materials Science and Engineering (Aberdeen: IOP Publishing).

Wei, J., Vo, T., and Inam, F. (2015). Epoxy/graphene nanocomposites-processing and properties: a review. RSC Adv. 5, 73510-73524. doi: 10.1039/C5RA13897C

Wu, J., Chen, J., Zhao, Y., Liu, W., and Zhang, W. (2016). Effect of electrophoretic condition on the electromagnetic interference shielding performance of reduced graphene oxide-carbon fiber/epoxy resin composites. Compos. Part B Eng. 105, 167-175. doi: 10.1016/j.compositesb.2016.08.042

Wu, J., Ye, Z., Ge, H., Chen, J., Liu, W., and Liu, Z. (2017). Modified carbon fiber/magnetic graphene/epoxy composites with synergistic effect for electromagnetic interference shielding over broad frequency band. J. Colloid Interface Sci. 506, 217-226. doi: 10.1016/j.jcis.2017.07.020

Xiang, D., Wang, L., Tang, Y., Harkin-Jones, E., Zhao, C., Wang, P., et al. (2018a). Damage self-sensing behavior of carbon nanofiller reinforced polymer composites with different conductive network structures. Polymer 158, 308-319. doi: 10.1016/j.polymer.2018.11.007

Xiang, D., Wang, L., Tang, Y., Zhao, C., Harkin-Jones, E., and Li, Y. (2018b). Effect of phase transitions on the electrical properties of polymer/carbon nanotube and polymer/graphene nanoplatelet composites with different conductive network structures. Polymer Int. 67, 227-235. doi: 10.1002/pi.5502

Yang, J., Xiao, J., Zeng, J., Bian, L., Peng, C., and Yang, F. (2013). Matrix modification with silane coupling agent for carbon fiber reinforced epoxy composites. Fibers Polymers 14, 759-766. doi: 10.1007/s12221-0130759-2

Yao, H., Hawkins, S. A., and Sue, H. (2017a). Preparation of epoxy nanocomposites containing well-dispersed graphene nanosheets. Compos. Sci. Technol. 146, 161-168. doi: 10.1016/j.compscitech.2017.04.026

Yao, X., Gao, X., Jiang, J., Xu, C., Deng, C., and Wang, J. (2018). Comparison of carbon nanotubes and graphene oxide coated carbon fiber for improving the interfacial properties of carbon fiber/epoxy composites. Compos. Part B Eng. 132, 170-177. doi: 10.1016/j.compositesb.2017.09.012

Yao, X., Jiang, J., Xu, C., Zhou, L., Deng, C., and Wang, J. (2017b). Improved interfacial properties of carbon fiber/epoxy composites through graphene oxide-assisted deposition of carbon nanotubes on carbon fiber surface. Fibers Polymers 18, 1323-1329. doi: 10.1007/s12221-017-1013-0

Yourdkhani, M., Liu, W., Baril-Gosselin, S., Robitaille, F., and Hubert, P. (2018). Carbon nanotube-reinforced carbon fibre-epoxy composites manufactured by resin film infusion. Compos. Sci. Technol. 166, 169-175. doi: 10.1016/j.compscitech.2018.01.006

Zanjani, J. S. M., Okan, B. S., Menceloglu, Y. Z., and Yildiz, M. (2016). Nanoengineered design and manufacturing of high-performance epoxy matrix composites with carbon fiber/selectively integrated graphene as multi-scale reinforcements. RSC Adv. 6, 9495-9506. doi: 10.1039/C5RA23665G
Zanjani, J. S. M., Okan, B. S., Pappas, P., Galiotis, C., Menceloglu, Y. Z., and Yildiz, M. (2018). Tailoring viscoelastic response, self-heating and deicing properties of carbon-fiber reinforced epoxy composites by graphene modification. Compos. Part A Appl. Sci. Manufact. 106, 1-10. doi: 10.1016/j.compositesa.2017.12.008

Zhang, L., Liang, J., Huang, Y., Ma, Y., Wang, Y., and Chen, Y. (2009). Sizecontrolled synthesis of graphene oxide sheets on a large scale using chemical exfoliation. Carbon 47, 3365-3368. doi: 10.1016/j.carbon.2009.07.045

Zhang, R., Gao, B., Du, W., Zhang, J., Cui, H., Liu, L., et al. (2016a). Enhanced mechanical properties of multiscale carbon fiber/epoxy composites by fiber surface treatment with graphene oxide/polyhedral oligomeric silsesquioxane. Compos. Part A Appl. Sci. Manufact. 84, 455-463. doi: 10.1016/j.compositesa.2016.02.021

Zhang, R., Gao, B., Ma, Q., Zhang, J., Cui, H., and Liu, L. (2016b). Directly grafting graphene oxide onto carbon fiber and the effect on the mechanical properties of carbon fiber composites. Mater. Des. 93, 364-369. doi: 10.1016/j.matdes.2016.01.003

Zhang, X., Fan, X., Yan, C., Li, H., Zhu, Y., Li, X., et al. (2012). Interfacial microstructure and properties of carbon fiber composites modified with graphene oxide. ACS Appl. Mater. Interfaces 4, 1543-1552. doi: 10.1021/am201757v

Zhao, M., Meng, L., Ma, L., Ma, L., Yang, X., Huang, Y., et al. (2018). Layer-bylayer grafting CNTs onto carbon fibers surface for enhancing the interfacial properties of epoxy resin composites. Compos. Sci. Technol. 154, 28-36. doi: 10.1016/j.compscitech.2017.11.002

Zhao, Z., Teng, K., Li, N., Li, X., Xu, Z., Chen, L., et al. (2017). Mechanical, thermal and interfacial performances of carbon fiber reinforced composites flavored by carbon nanotube in matrix/interface. Compos. Struct. 159, 761-772. doi: 10.1016/j.compstruct.2016.10.022

Zhou, C., Gu, A., Liang, G., and Xia, Y. (2015). Tough silica-hybridized epoxy resin/anhydride system with good corona resistance and thermal stability for permanent magnet synchronous wind-driven generators through vacuum pressure impregnation. Ind. Eng. Chem. Res. 54, 7102-7112. doi: 10.1021/ie504737g

Zhu, Y., Ji, H., Cheng, H., and Ruoff, R. S. (2017). Mass production and industrial applications of graphene materials. Nat. Sci. Rev. 5, 90-101. doi: 10.1093/nsr/nwx055

Zhu, Y., Murali, S., Cai, W., Li, X., Suk, J. W., Potts, J. R., et al. (2010). Graphene and graphene oxide: synthesis, properties, and applications. Adv. Mater. 22, 3906-3924. doi: 10.1002/adma.201001068

Conflict of Interest Statement: The authors declare that the research was conducted in the absence of any commercial or financial relationships that could be construed as a potential conflict of interest.

Copyright (c) 2019 Keyte, Pancholi and Njuguna. This is an open-access article distributed under the terms of the Creative Commons Attribution License (CC BY). The use, distribution or reproduction in other forums is permitted, provided the original author(s) and the copyright owner(s) are credited and that the original publication in this journal is cited, in accordance with accepted academic practice. No use, distribution or reproduction is permitted which does not comply with these terms. 